\title{
Self-Citation, Cumulative Advantage, and Gender Inequality in Science
}

\author{
Pierre Azoulay, ${ }^{a}$ Freda B. Lynn ${ }^{b}$
}

a) Massachusetts Institute of Technology; b) University of lowa

Abstract: In science, self-citation is often interpreted as an act of self-promotion that (artificially) boosts the visibility of one's prior work in the short term, which could then inflate professional authority in the long term. Recently, in light of research on the gender gap in self-promotion, two large-scale studies of publications examine if women self-cite less than men. But they arrive at conflicting conclusions; one concludes yes whereas the other, no. We join the debate with an original study of 36 cohorts of life scientists (1970-2005) followed through 2015 (or death or retirement). We track not only the rate of self-citation per unit of past productivity but also the likelihood of self-citing intellectually distant material and the rate of return on self-citations with respect to a host of major career outcomes, including grants, future citations, and job changes. With comprehensive, longitudinal data, we find no evidence whatsoever of a gender gap in self-citation practices or returns. Men may very well be more aggressive self-promoters than women, but this dynamic does not manifest in our sample with respect to self-citation practices. Implications of our null findings are discussed, particularly with respect to gender inequality in scientific careers more broadly.

Keywords: self-citation; cumulative advantage; science careers; gender inequality; self-promotion

Citation: Azoulay, Pierre, and Freda B. Lynn. 2020. "SelfCitation, Cumulative Advantage, and Gender Inequality in Science." Sociological Science 7: 152-186.

Received: March 23, 2020

Accepted: March 29, 2020

Published: May 6, 2020

Editor(s): Jesper Sørensen, Olav Sorenson

DOI: $10.15195 /$ v7.a7

Copyright: (C) 2020 The Author(s). This open-access article has been published under a Creative Commons Attribution License, which allows unrestricted use, distribution and reproduction, in any form, as long as the original author and source have been credited. (C) (i)
CIEnTISTS thrive in their disciplines when they produce work that is widely read. $\mathcal{S}$ But like any other competitive market, producers must vie for attention from consumers overwhelmed with options. That scientists engage in self-promotion to sell their goods has long been acknowledged (e.g., Nelkin 1987; Garfield 1987a; Azoulay, Fons-Rosen, and Graff Zivin 2019) and is viewed by some as part and parcel of "getting ahead" in the business (e.g., Reis 1999; Fiske 2018). For example, self-citing-whether intellectually relevant or not-is often interpreted as a strategy that authors use to boost the visibility of their prior work, which could in turn build professional authority (Fowler and Asknes 2007; but see Medoff 2006).

One strand of research on self-citation focuses specifically on whether this promotional practice varies by gender (see King et al. 2017; Mishra et al. 2018). A growing area of research on gender, self-assessment, and self-promotion gives reason to believe that women may be less likely to pounce on the opportunity to self-cite (Exley and Kessler 2019; Lerchenmueller, Sorenson, and Jena 2019). First, researchers show that women evaluate their performances more critically than men even when they perform objectively as well (Correll 2001, 2004; Exley and Kessler 2019). For example, Reuben and colleagues $(2012,2014)$ find that, in the context of mathematics performance, women tend to retrospectively characterize themselves as having performed worse than their actual score, whereas men tend to remember themselves as having performed better than their actual score.

Second, women are more likely to be sanctioned for engaging in behaviors interpreted as self-promotion. Prescriptive gender norms are dominant role expectations 
(i.e., cultural beliefs) regarding what men and women "should" or "should not" be (Eagly and Karau 2002), and a long line of research shows that men are expected to behave in an agentic manner (assertive and self-reliant), whereas women are expected to behave in a communal manner (caring and other-oriented) (see Auster and Ohm 2000). Self-promotion for women is thus considered counterstereotypical behavior, which can lead to backlash. For example, in an experimental hiring study, Rudman (1998) shows that women who highlight their accomplishments are penalized in terms of their likability and hireability.

King et al. (2017) argue that these same socialization processes may result in men self-citing publications at a greater rate than women (see p. 2 and p. 15), which in turn could partially explain why women on average lose out to men over the career course in science (see pp. 2-3). This argument could be distilled into three related but distinct empirical questions: (1) are men compared with women, ceteris paribus, more likely to engage in self-citation per unit of past productivity, (2) are men compared with women, ceteris paribus, more likely to engage in self-citation as a means of gratuitous self-promotion, and (3) do men's self-citations relative to women's generate greater returns with respect to future citations? That is, do the self-promotional efforts of men pay off more for men than for women authors?

The purpose of this study is to provide an empirical test of each of these arguments using a novel, longitudinal data set of life scientists and their career trajectories. Currently, there are two large-scale studies (King et al. 2017; Mishra et al. 2018) that address the first hypothesis regarding gender and (direct) self-citation patterns, but neither one addresses the second and third hypotheses. Yet all three, we argue, are needed to understand the role of self-citation in producing career inequality in science. Furthermore, although our sample includes only a select group of researchers from one domain in science, the comprehensive career data employed in this study provide an important contrast to the publication samples employed by both King et al. (2017) and Mishra et al. (2018). Their samples contain a large number of articles published in multiple decades, but these publications are analyzed in light of very limited information (or none in the case of King et al. [2017]) regarding the scientist, such as career age. For example, if 50 percent of publications in the sample belong to young women scientists with nothing to self-cite and 50 percent of publications in the sample belong to elderly men with many publications to self-cite, the rate of self-citation will appear to be higher for men even if gender has zero correlation with self-citation rate. We sidestep these potential composition effects by instead comparing men and women (and some transgendered individuals) at specific points in their career course.

\section{Background}

\section{Self-Citation in Science}

Self-citations can be construed from different perspectives. The focus of this study is direct self-citations, which occur when an author publishes an article that references one of their past publications or working papers. Self-citations can also occur through collaborators. For example, when one subset of a large group of 
collaborators references articles produced by another nonoverlapping subset of collaborators from the same umbrella project, this constitutes a team-based form of self-citation even though there are no direct, individual-level self-citations (Ioannidis 2015). Finally, self-citation can come in the form of "coercive induced citation," wherein author A pressures author B to cite publications authored by A (Ioannidis 2015). This pressure can come, for example, from reviewers and editors during the peer review process (Thombs et al. 2015). ${ }^{1}$

Overall, the practice of direct self-citation is quite common. A large-scale analysis of synchronous (outgoing) citations suggests that roughly 9 percent of all citations are direct self-citations (King et al. 2017), although the percentage is higher in some disciplines (e.g., physical sciences) than others (e.g., humanities) (see Mishra et al. 2018; Snyder and Bonzi 1998; Lawani 1982; Tagliacozzo 1977). Diachronous (incoming) self-citation rates are generally even higher in a short observation window, such as the first three or five years after publication. For example, using a three-year citation window for a large sample of articles published in the natural sciences, Asknes (2003) finds that 36 percent of incoming citations are direct self-citations and that multiauthored articles have more self-citations.

Although self-citations can indeed be intellectually relevant (Hyland 2003; see also Bonzi and Snyder 1991) and hence appropriate and "even necessary" (Ioannidis 2015), the practice of self-citing on balance is still construed in a negative light and as a practice that requires correction (Fowler and Asknes 2007; MacRoberts and MacRoberts 1989). The disdain comes from the fact that at least some self-citations can be interpreted as gratuitous acts of self-promotion, which is antithetical to the deeply rooted assumption that science is supposed to be governed by the norms of universalism and disinterestedness (Merton [1942] 1973; Garfield 1987b). Not surprisingly, it is recommended that self-citations be removed from the calculation of career citation metrics as a way of discounting self-promotional efforts (e.g., Fowler and Asknes 2007). Of course, such a fix only addresses the direct effect of self-citations and cannot magically reveal a scientist's "true" career citation trajectory had self-citations never entered the trajectory. Perhaps because of the difficulty of estimating the true causal effect of self-citations on career citation accumulation, the practice of self-citing continues to be associated with "gaming the system" (Ioannidis 2015):

So, here is a recipe for 'success': co-author more papers (salami slicing, elimination of quality checks, undeserved co-authorship and acceptance of gifts from ghosts can all help); ignore unfavourable reviewer comments; keep submitting until you find a hole in the peer-review system; self-cite; and expect random citations. While the recipe will probably not earn its practitioners a Nobel Prize, it can still open many doors unfortunately (Ioannidis, Tatsioni, and Karassa 2010:286).

\section{Gender and Self-Citation Rate}

King et al. (2017) make a compelling argument for why gender patterns in selfcitation need to be examined. Because self-citation can "seriously affect the appearance of scholarly influence" (2017:2), a gender difference in self-citation aggressive- 
ness could lead to a "non-merit" based gender gap in scholarly influence over the career course, which could in turn, generate other forms of career inequality. The underlying concern is that men could potentially be "getting ahead" faster than women because they are (consciously or not) more comfortable puffing themselves up and are more aggressive about selling their work relative to women, who may anticipate backlash from self-promotional efforts and hence not engage. In addition, as we argue in more depth below, men who engage in self-citation might see greater returns to self-promotional efforts compared with women.

To date, two major studies have been conducted on gender and rate of direct self-citation. In a large-scale study of 1.5 million articles from the JSTOR corpus, King et al. (2017) find that men self-cite at a much higher than women. For example, they calculate that the rate of self-citation for their sample (1970-2011) to be 70 percent higher for men than women. The magnitude of this aggregate difference is shocking. They title their article, "Men set their own cites high."

Although such evidence is consistent at face value with the conjecture that men are more aggressive salesman than women, King et al. (2017) are careful to note that multiple mechanisms could produce such a finding. On the one hand, their finding could reflect that men, ceteris paribus, are more aggressive about promoting their work through self-citation (perhaps because they evaluate themselves more positively than women) and that this difference in salesmanship is what leads directly to the marked gender gap in self-citation they observe in their sample. On the other hand, the observed difference in self-promotion could be a simple artifact of some authors having a greater number of previous publications (or working papers) to self-cite (see King et al. [2017:15-16]). To this point, in a supplementary analysis of a sample of more than 400,000 Social Science Research Network (SSRN) articles, King et al. (2017:17) find no gender gap in self-citation when controlling for an author's total number of SSRN research articles. In other words, women and men authors in the SSRN self-cite at the same rate once accounting for past productivity.

Following their lead, Mishra et al. (2018) examine a large corpus of biomedical articles in PubMed and similarly unpack gender patterns of outgoing self-citations. They find that once the number of past publications is accounted for, men and women self-cite at the same rate. That is, women and men with the same opportunity to self-cite appear to self-cite as the same rate. They title their study, "Self-citation is the hallmark of productive authors, of any gender."

Together, these two studies significantly advance our empirical understanding of one of the three main questions at stake. Are men compared with women more likely to engage in self-citation per unit of past productivity? The answer appears to be "No"; when accounting for the number of articles published prior to the focal article, there is strong evidence to suggest that men and women self-cite at the same rate (Mishra et al. 2018; see also King et al. [2017:17]). We can thus deduce that the large gender gap in self-citations observed by King et al. (2017) is most likely the byproduct of past productivity; men publish a notably larger number of more articles than women (West et al. 2013) and thus have far greater opportunity to self-cite. 


\section{Gender and Self-Citation Type}

But even if men tend to self-cite at the same rate as women after adjusting for opportunity, it remains possible that men and women self-cite in a qualitatively different manner. For example, in line with past research showing that women are more self-critical than men about their performances (e.g., Correll 2001; Reuben et al. 2014), it could be that men might use more boastful or authoritative language when citing their past work. In a similar vein, women might have higher standards than men in terms of what constitutes intellectual relevance when self-citing past work. For instance, although empirical studies of research specialization suggest that men are more likely than women to specialize (Leahy 2006, 2007), when men do branch out to new topics, they might feel more comfortable drawing on their authority derived in one area to establish credibility in a new area, which could further career development in the long term. In contrast, perhaps when women move into new areas of research, they refrain from self-citing their previous work because they view it as too far afield. Bottom line: the average self-citation rate between men and women could be similar, but the nature or intent of self-citation could differ.

\section{Gender and the Long-Term Impact of Self-Citations}

Moreover, what if men and women self-cite at the same rate but the downstream impact of each self-citation varies by gender? As King et al. (2017:2) remind us, the importance of studying self-citations is rooted in their potential to shape the long game:

Certainly, a scholar must write a reasonable number of papers for selfcitation to have an effect early in his or her career; but in fields such as a biology, self-citations can have an effect on career outcomes as early as first job search, and certainly by tenure stage. The cumulative record of citations (or lack thereof) from other scholars' citations that results from an authors' self-citation patterns can seriously affect the appearance of scholarly influence.

Fowler and Aksnes (2007:433), for example, find that every additional selfcitation nets an author an additional 3.65 other-citations within ten years, leading them to conclude that "self-citation advertises not only the article in question, but the authors in question."

What is unclear, however, is if all authors benefit equally when self-citing. Marketing efforts, after all, can vary in their effectiveness and sometimes even backfire. A self-citation is a successful sales pitch to the extent that it persuades readers of the author's authority and expertise and compels the reader to pay attention to or track down the self-cited work. In contrast, a self-citation would be (1) ineffective if it mobilizes no interest in the referenced work, or worse, (2) potentially harmful if negatively interpreted as boastful or gratuitous.

Past research makes a case for why men's self-citations relative to women's might have a more positive impact on career growth. First, there are still strong 
normative prescriptions that men are supposed to be assertive and women communal (Auster and Ohm 2000; Koenig 2018). Second, men continue to be judged as more competent than women (see Ridgeway 2011; Moss-Rascusin et al. 2012; Thébaud 2015; Leslie et al. 2015; Bian, Leslie, and Cimpian 2017), and third, research demonstrates that women face backlash for highlighting accomplishments (Rudman 1998; Moss-Racusin, Phelan, and Rudman 2010). Taken together, past research suggests that readers will respond differently to self-citations made by men versus women. If women's self-citations are more likely to fall on deaf ears or be viewed in a negative light, early self-citations for women would not convert to gains in scholarly influence or career achievement in the same way as it would for men.

\section{Career and Research Productivity Data for 3,667 Life Scientists}

We address all three questions regarding rate, type, and impact of self-citation by conducting a longitudinal study of the winners of postdoctoral fellowships awarded by four U.S.-based private philanthropic foundations: the Damon Runyon Cancer Research Foundation (1970-2005), the Jane Coffin Childs Memorial Fund for Medical Research (1970-2005), the Helen Hay Whitney Foundation (1970-2005), and the Life Sciences Research Foundation (1983-2005) —a total of 3,667 life scientists.

These fellowships confer on their winners an early marker of success and are prestigious accolades ambitious graduate students in the life sciences can receive as they contemplate the next phase of their careers-a postdoctoral experience. Of note, these four foundations select their recipients from identical pools in very similar ways: a dossier that includes articles published, letters of recommendation, and the outline of an independent research agenda, followed by an evaluation by a panel of distinguished scientists, typically composed of former recipients. In summary, our sample is composed of "star" graduate students. Of course, at such an early career stage, these individuals have not stepped out of the shadow cast by their graduate school mentor, and as a result there is no guarantee that this early success will endure.

By sampling on winners of just these four prestigious, merit-based awards, we are confident that our sample is relatively homogenous in terms of scholarly potential, a difficult to observe characteristic. That said, we are aware that a recent study (Ginther and Heggeness 2020) raises the issue of administrative discretion in allocating supposedly merit-based awards in science. They find that discretion is widely used by program officers when allocating the National Institutes of Health (NIH) F32 National Research Service Award, a grant given to "high-potential, earlycareer scientists" in the biomedical sciences. Although the award is undoubtedly still a selective prize, Ginther and Heggeness (2020) show that award winners include more applicants "reached for" through discretionary decisions compared with applicants funded based on high peer review scores alone. Unfortunately, we do not have access to reviewer scores from the private fellowships on which our sample is based and thus cannot directly examine the reward allocation process of these private fellowships à la Ginther and Heggeness (2020). We strongly suspect, 
however, that heterogeneity in scholarly potential is limited in our sample compared with the F32 award given that our fellowships are controlled by private foundations and the total number of awards per year is far lower compared with the F32. In sum, we proceed under the assumption that members of each cohort in our sample are starting their careers in very similar positions.

Moving forward, we track the careers of each individual from the receipt of their MD or PhD forward until retirement, death, or 2015. ${ }^{2}$ Through CVs, NIH biosketches, web searches, and publicly available databases, we collect and disambiguate publications, references, citations, NIH grants, and patents. In addition, we record the year in which each scientist exits science, exits academia, or in the subsample of academics, exits from a "stable" to a "marginal" position-that is, one where they can no longer control the direction of their investigations.

Although this group of scientists is not a random sample of the postdoctoral population, these cohort data provide an important counterpoint to the JSTOR and PubMed samples used by King et al. (2017) and Mishra et al. (2018), respectively. These samples contained an impressively large number of articles but little to no background information on the men and women scientists themselves. In contrast, our cohort sample consists of graduate students similarly poised to succeed in their field with all the major components of their careers tracked across several stages.

This approach, we argue, is critical to producing interpretable results with respect to our three research questions. This is particularly a challenge for our third question, which pertains to how self-citation behavior may or may not convert to other career rewards over time. The difficulty with studying cumulative advantage is being able to confidently locate it in a sea of unobserved heterogeneity (DiPrete and Eirich 2006). We argue that this type of rich, longitudinal cohort data may be the best method of isolating supply-side factors short of running an actual experiment. In sum, we cannot make generalizations about self-referencing behavior that apply to the universe of scientists, but we can at least draw crisp conclusions for some.

\section{Data}

Our data collection starts with 3,713 fellowship winners between 1970 and 2005 for the four private foundations mentioned above. Despite exhaustive efforts to track their career history, we lose 28 scientists ( 0.75 percent) to follow up, yielding a sample of 3,685 scientists for whom we have complete information. We lose a further six individuals who died during training, two who exited science the year after starting their fellowship, and ten who have either no original publications or no citations at all. The final analytic sample contains information about 3,667 scientists (98.76 percent of the original sample, 2,546 [69.4 percent] men scientists vs. 1,014 women scientists [27.6 percent]).

Scientific careers can be fragile, especially for novices (Hill 2018). Only a small fraction of all scientists who complete a postdoctoral fellowship secure a full-time academic position (McGinnnis, Allison, and Long 1982; Mantovani, Look, and Wuerker 2006; Levitt 2010; Silva et al. 2016). The biomedical research setting is interesting because the biopharmaceutical industry is a reliable employer for the scientists we study, and individuals who transition to industry often conduct 
scientific investigations using methods, techniques, and materials similar to those used by academic scientists (Zucker, Darby, and Torero 2002).

Even though members of each cohort are starting their careers in very similar positions because of our research design, career pathways within cohorts can diverge considerably over time. The unique strength of our longitudinal data set is that we account for every career transition for the scientists in the data. A full 73.0 percent of the scientists in the sample begins their career as principal investigators in traditional academic positions within a university, academic medical center, or research institute (67.6 percent end their career in such a position, or at least remain in one at the end of the observation period). This prevalence of traditional tenuretrack positions underscores the extent to which scientists enter our sample only if they show extraordinary promise in graduate school.

Table 1 provides descriptive statistics at the individual level, broken down by gender. Women scientists are almost three years younger on average, relative to men, reflecting a doubling of women's share of fellowships between the early part of the sample (15.5 percent, 1970-1974) and the later part (32.0 percent, 2001-2005). Large gender disparities are evident in these univariate comparisons. On average, women scientists in the sample publish less ( 34 vs. 56$)$, receive less citations (2,032 vs. 3,819 ), and receive less NIH funding ( $\$ 4.3$ million vs. $\$ 8.0$ million) than men in the sample. They spend a year longer in training on average and are less likely to begin their career as principal investigator in academia (64.7 percent vs. 76.4 percent) and more likely to find themselves in a "marginal" scientific position (e.g., employed as a technician in someone else's laboratory, adjunct teaching position, etc.). They also appear less prone to self-reference ${ }^{3}$ their work when they do publish-their selfreference share is 5.2 percent, versus 7.0 percent for men scientists, which dovetails with the raw comparisons provided by King et al. (2017) and Mishra et al. (2018). Univariate comparisons can only go so far, however. Because the proportion of fellowships awarded to women increases over time, it is possible that gender gaps in productivity merely reflect compositional changes, with women scientists having fewer career years on average to accumulate publications, citations, and funding. Our statistical models will fully account for compositional shifts including a full suite of calendar year effects in all specifications.

Figure 1 depicts the gender gap in publication rates graphically by first decomposing every scientist's career in nine distinct temporal sequences: graduate school, postdoctoral training, the first five years of the "independent" (i.e., post-training) career, years 5 through 10, years 10 through $15, \ldots$, and a residual category corresponding to those in their 30th career year or later (Panel A). A disparity in publication rates is apparent at every career stage, even graduate school-the period that directly led each individual in the sample to be selected for one of these four elite fellowships. $t$ tests reveal that the gaps are statistically significant in each stage, though the magnitude varies: initially small, the gap grows in the early and midindependent career, before leveling of somewhat after year 25 (relatively few observations identify the spike at career age 30 or later). Panel B displays the same information by individual career year, with the career clock starting in the year of $\mathrm{PhD}$ receipt. These decompositions hint that gender disparities in publication rates in this sample are not a mere artifact of composition effects. ${ }^{4}$ 


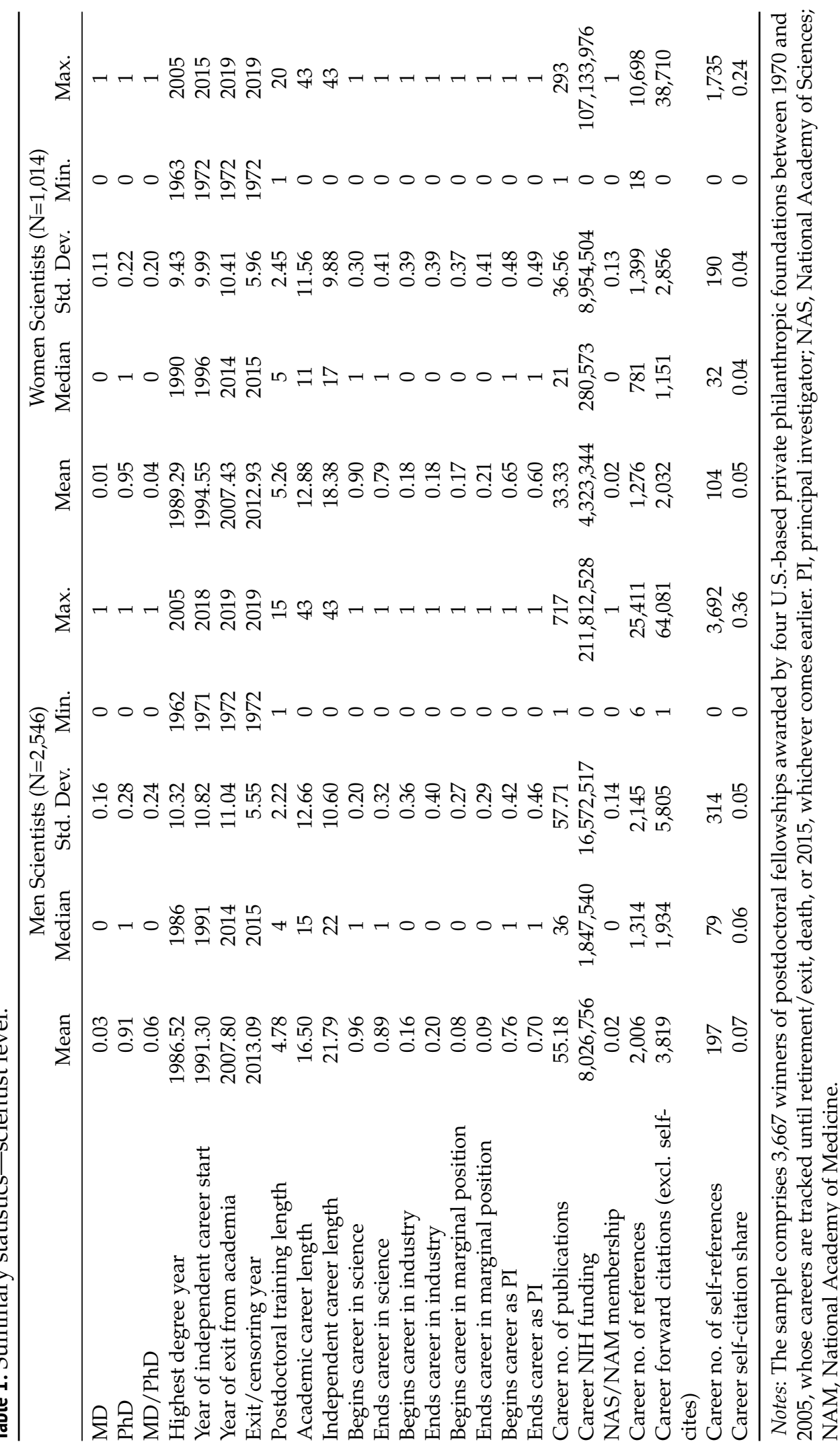




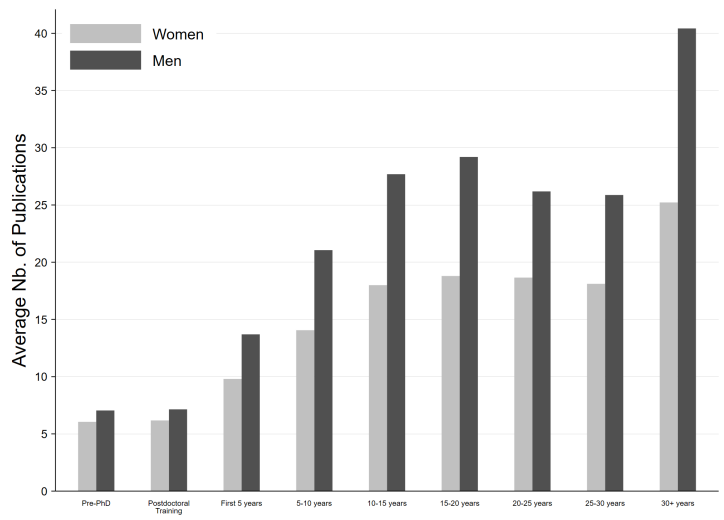

(a) By career sequence

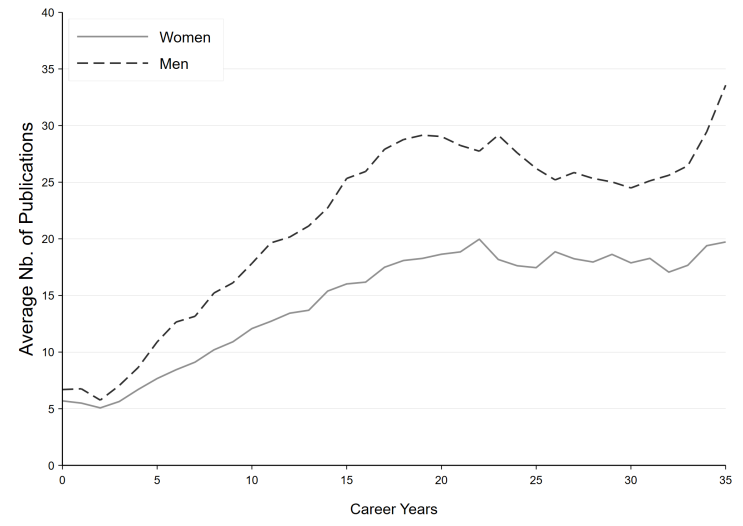

(b) By career year

Figure 1: Publication rates-scientist level. Notes: Publication rates by gender over the career by career sequence (Panel A) and individual year (Panel B). In Panel A, $t$ tests indicate that the difference between publication rates for men and women is statistically significant at the 1 percent level at every career stage. In Panel B, year 0 corresponds to the year of PhD receipt. In both panels, but especially Panel B, recall that the number of scientists in the cells corresponding to the most advanced stage of the career is relatively small (for example, in year 35, we observe only 452 scientists -372 men and 80 women). The remainder of the sample has either exited already or is not yet "of age," as they entered in the sample after 1980 and the last year of observation is 2015 .

Figure 2 unpacks the self-reference share further. Panel A displays the histogram for its distribution. Women scientists are more represented than men scientists below the median (0.05). In the top two quartiles, the gender differences are less pronounced. Panel B displays the average self-reference share by year of career (year zero corresponds to the year of $\mathrm{PhD}$ receipt) for men and women scientists. It grows monotonically for the first 20 years of the career, with the gap between men and women remaining quite stable until at least 20 years post$\mathrm{PhD}$. Thereafter, we find some evidence of convergence, with women scientists "catching up" in their propensity to reference their own work. Panel C performs a similar exercise but breaks down the career into distinct sequences: graduate school, postdoctoral fellowship, and the independent career in five-year increments. Our first observation is that the gender differences, though clearly noticeable, are not especially stark and certainly smaller in magnitude than those documented by King et al. (2017) and Mishra et al. (2018). Second, the gap is present "at birth" (in graduate school), even though these individuals have presumably little work to self-reference at that stage, and subsequently grows until midcareer. After that point, the gap appears to shrink and even seemingly reverses after 30 or more years of active career. This last result needs to be interpreted with caution because only those in the early fellowship years get observed for 30 years or more, and this portion of the sample is dominated by men.

Table 2 displays descriptive statistics for the individual articles published by men $(\mathrm{N}=144,185)$ and women $(\mathrm{N}=35,131)$ scientists. Gender differences at this level of analysis are much less apparent than at the individual level. On average, articles 


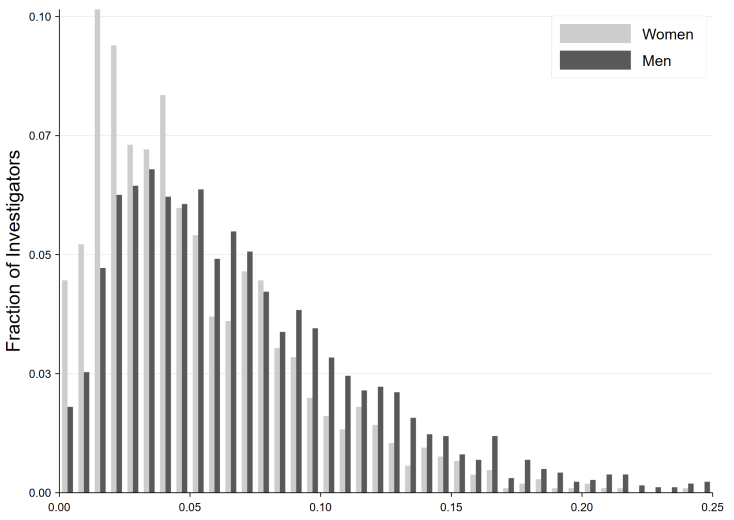

(a) Over the whole career.

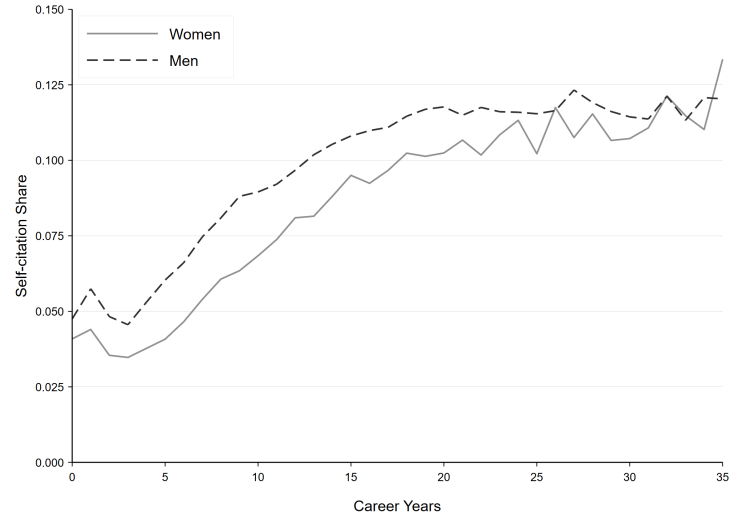

(b) Over time.

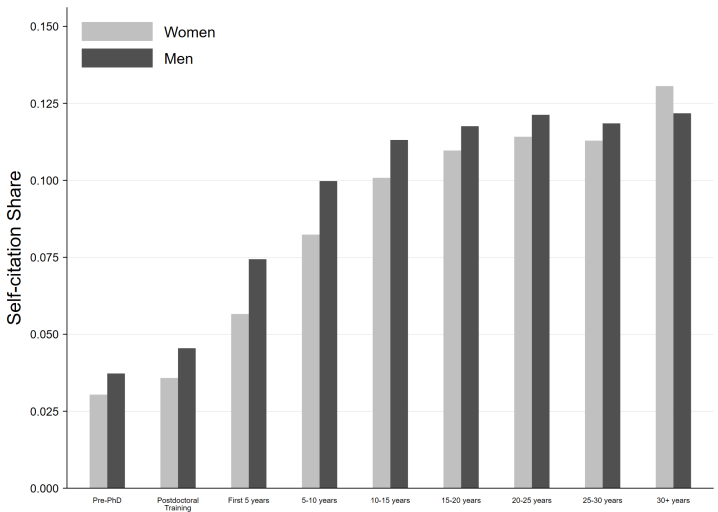

(c) By career sequence.

Figure 2: Self-reference rates—scientist level.

written by men receive 68.96 citations versus 62.1 for those authored by women, but the medians are closer ( 26 vs. 27 , respectively). The self-reference share continues to be lower for women's articles (8.9 percent) relative to men's (10.8 percent).

Tables A1 and A2 in the online supplement provide a detailed breakdown of position "type" at the start of the career (i.e., immediately after the end of scientific training) and at the end of the observation period. ${ }^{5}$

\section{Publication and Citation Information}

The source of our publication data is PubMed, an online resource from the National Library of Medicine that provides fast, free, and reliable access to the biomedical research literature, with more than 40,000 journals indexed. We match PubMed records with those contained in Web of Science, whose coverage is slightly less deep, but which provides comprehensive citation information. This means that we only capture a reference if it appears in PubMed, which excludes books as well as articles appearing in important journals in fields adjacent to the life sciences, 


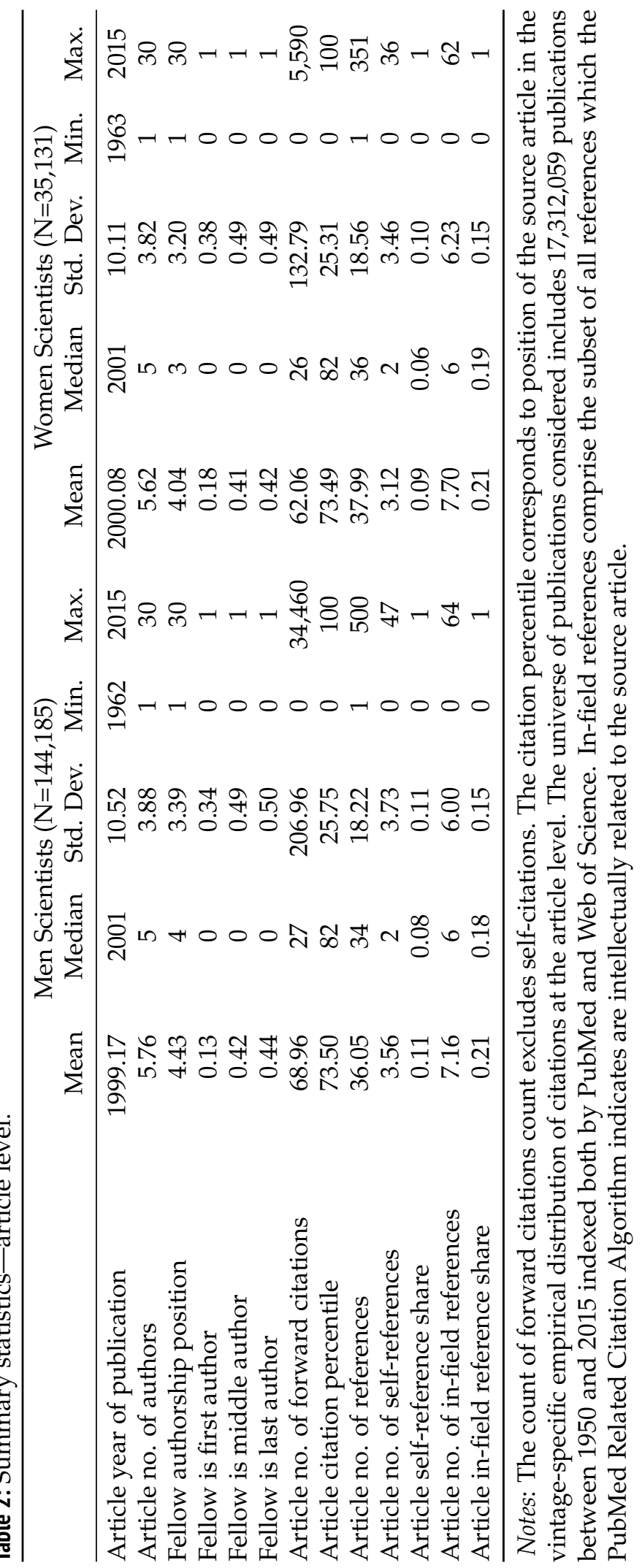


but not indexed by PubMed (inorganic chemistry and materials science come to mind as examples of such domains). In practice, this is not a large concern, as the correlation between citations with and without the PubMed restriction in Web of Science is 0.99 .

To distinguish between intellectually related and unrelated citations, we leverage the PubMed Related Citations Algorithm (PMRA) (Lin and Wilbur 2007), which relies on Medical Subject Headings (MeSH) but not in any way on citation or collaboration linkages. MeSH terms constitute a controlled vocabulary maintained by the National Library of Medicine that provides a very fine-grained partition of the intellectual space spanned by the biomedical research literature. Importantly for our purposes, MeSH keywords are assigned to each publication by professional indexers who focus solely on their scientific content.

We rely on PMRA to tag every reference to each of the source articles in the data as related (i.e., the article is one of the intellectual neighbors associated with the source according to PMRA) or unrelated. ${ }^{6}$ Turning back to Table 2, it appears that men and women scientists are as likely to cite "within field" as "outside the field."

\section{Methodological Considerations}

Mishra et al. (2018) studied the population of articles indexed by PubMed between 2002 and 2005 with algorithmically disambiguated publication. The essence of the exercise they performed was predicting the likelihood that a given reference corresponds to a previous article by at least one of the authors on a focal article, using a large set of covariates and machine learning techniques. Their work inspired our analysis, but our data and methodological approach differ in several ways.

First, the scientist populations differ. An obvious limitation of our data set, relative to theirs, is that it pertains to a narrower population along two dimensions. As prestigious fellowship recipients, they are on average more accomplished at baseline than would be the case for a random sample of $\mathrm{PhD}$ graduates, or even the population of academic scientists. The content of their research is also more restricted - molecular and cell biology and its applications to biomedicine-whereas Mishra et al. (2018) include all authors regardless of biomedical subfield. This narrow focus can be thought of as a threat to external validity, but it is more than compensated in our mind by our ability to follow scientists over time regardless of output (as opposed to sampling scientists on the basis of productivity in a narrow window of time) and to capture individual-level characteristics which may be important to understand the phenomenon of interest but require an intimate knowledge of scientists' career trajectories. Such covariates include degree received (i.e., $\mathrm{MD}$ in addition to $\mathrm{PhD}$ ), year of $\mathrm{PhD}$ receipt (which starts the career clock in our empirical specifications), length of postgraduate training period, and position "type" (e.g., tenure-track academic vs. "marginal" academic vs. industry, etc.).

Second, our measure of self-reference is more specific, as it pertains to a particular author on the authorship list of each of the 179,316 source articles in our sample. The mean level of self-reference in our data (10.4 percent) is therefore lower than in their work, or that of a broad measure of self-reference based on any overlap in author, as opposed to a focal author. We likely measure self-reference with less 
error because our disambiguation of each author's bibliome is based an individual dossier for each fellow, whereas theirs relies on a large-scale disambiguation effort (Torvik and Smalheiser 2009), which necessarily performs less well for frequent names.

Third, whereas their measure of gender is imputed algorithmically based on first name, we measure gender based on a host of contextual cues-including name, photographs, and pronoun usage, all of which are embedded in the rich information compiled for each scientist. ${ }^{7}$ This is preferable because our sample includes a high proportion of foreign-born scientists for whom gender imputation might perform less well.

Fourth, because our objective is not prediction, but an assessment of the magnitudes of gender disparities in self-reference behavior, we saturate our models with a battery of control covariates that help us provide an "apples-to-apples" comparison between the behavior of men and women scientists while preserving our ability to interpret the empirical magnitude of the effect. These include a full suite of journal indicator variables, authorship length effects, author position effects, indicator variables for different reference vintages and age, and indicator variables for each source article's forward citation impact. In other words, the estimates we present below correspond to the following notional experiment:

Consider two articles that appeared in the same journal, in the same year, with the same number of authors, and that will go on to be equally well cited (excluding self-citations) in the future, but differ in the gender of the fellowship recipient that appears on the authorship roster (although the men and women authors of interest appear on the same position on the list, i.e., first, middle, or last position). Consider now the backward references in each article (with the additional proviso that only references of the same vintage are being compared). What is the expected probability that such a reference corresponds to a selfreference if the article is authored by a man versus a woman?

In practice, in a data set composed of all citation linkages between a focal article and their references, we estimate specifications of the following type:

$$
\begin{aligned}
E\left[\operatorname{sel}_{i j}=1 \mid X_{i j}, k(i), \varphi(i), t(i), \psi(i)\right]=\beta_{0} & +\beta_{1} \text { WOMAN }_{k(i)} \\
& +\beta_{2} \operatorname{RELATED} D_{i j} \\
& +\beta_{3} \operatorname{Ln}\left(\operatorname{STOCK}_{-} P U B S_{k(i), t(i)-1}\right) \\
& +\beta_{4} X_{i j}+\delta_{\psi(i)}+\gamma_{\psi(j)} .
\end{aligned}
$$

For each article $i$ published by fellow $k(i)$ in year $t(i)$ and referencing article $j$, we use a linear probability model to specify the conditional mean of the probability of self-reference $\operatorname{self}_{i j}$ as a function of the focal author's gender $\left(W O M A N_{k(i)}\right)$, an intellectual relatedness indicator variable (RELATEDNESS $i j$, defined in more detail below), the log of the number of citable items for author $k(i)$ in year $t(i)$, and $\delta_{\phi(i)}$ (respectively, $\gamma_{\psi(i)}$ ), a high-dimensional vector of fixed effects corresponding to characteristics of articles $i$ (respectively, $j$ ) -for example, the journal in which $i$ appeared, the age of article $j$ in year $t(i)$, the number of authors for $i$, and so on. 
$X_{i j}$ is a vector of predetermined covariate (e.g., fellowship sponsor and fellowship award year for each scientist $i$ ).

Our choice of a linear probability model (LPM) deserves mention given its lack of popularity in empirical sociological research. Because an LPM may generate fitted values outside of the interval [0;1], its use would not be appropriate for a predictive type of analysis. However, our objective here is not prediction but the estimation of the marginal effects from the conditional expectation function. For this purpose, the LPM is typically more appropriate (Angrist and Pischke 2008:94-106). Moreover, nonlinear models such as the probit and logit are not well suited to the use of fixed effects because of the incidental parameter problem (Neyman and Scott 1948).

An additional analysis explores whether the rate of self-reference changes over the career course, something neither King et al. nor Mishra et al. attended to in their analyses. For example, there could be no aggregate difference between men and women scientists in the rate of self-referencing controlling for past productivity, and yet men could be much more likely to self-reference at early career stages, whereas women's self-references disproportionately occur in later career stages. In a similar vein, as suggested by King et al. (2017), the rate of self-reference (as well as the gender differential in self-reference) possibly changes over time. Therefore, we also examine whether self-reference patterns differ between earlier and later cohorts.

\section{From Self-Reference to Self-Promotion}

Across multiple domains, there has been an accumulation of empirical evidence that self-promotional behavior is more frequent among men than women (e.g., Correll 2001, 2004; Reuben et al. 2012; Exley and Kessler 2019; Lerchenmueller et al. 2019). But a case can be made that self-reference is a relatively crude proxy for self-promotion in the context of scientific research, because reasons to reference one's past work exist even in the absence of a self-aggrandizing motivation. ${ }^{8}$ We argue that a citation is more likely to reflect self-promotional behavior when the intellectual connection between the citing and cited items is more tenuous. In contrast, citation linkages between intellectually related articles are more likely to denote that one article builds on the ideas of the other. To capture relatedness, we make use of the PMRA, which helps distinguish between references coming from within the same narrow subfield, as opposed to outside this subfield. An interaction term between the woman scientist indicator variable and the relatedness indicator will shed light on whether men are more likely than women scientists to engage in self-reference as a means of gratuitous self-promotion, ceteris paribus.

\section{Returns to Self-References}

Finally, we use individual-level panel data models to examine whether men and women differ in the career and productivity returns to self-references. This type of analysis cannot tease out the underlying mechanism that might cause self-references to be more impactful, but at the very least we can estimate if a gender gap exists with respect to the conversion of self-references into publications, future citations, 
research grants, and career stability. We estimate the following ordinary least squares (OLS) specifications:

$$
\begin{aligned}
& E\left[y_{i t} \mid X_{i t}\right]=\beta_{0}+\beta_{1} W_{O M A N} \\
& +\beta_{2} \operatorname{Ln}\left(\text { STOCK_PUBS } S_{i t-1}\right) \\
& +\beta_{3} \operatorname{Ln}\left(\text { STOCK_PUBS } S_{i-1}\right) \times W O M A N_{i} \\
& +\beta_{4} \text { FRACSELF } F_{i t-1} \\
& +\beta_{5} \text { FRACSELF } F_{i t-1} \times W O M A N_{i} \\
& +\beta_{6}^{\prime} X_{i t}+\delta_{t} \text {, } \\
& E\left[y_{i t} \mid X_{i t}\right]=\beta_{0}+\beta_{2} \operatorname{Ln}\left(\text { STOCK_PUBS } S_{i t-1}\right) \\
& +\beta_{3} \operatorname{Ln}\left(\text { STOCK_PUBS } S_{i t-1}\right) \times \text { WOMAN } \\
& +\beta_{4} \text { FRACSELF } F_{i t-1} \\
& +\beta_{5} \text { FRACSELF } F_{i t-1} \times W O M A N_{i} \\
& +\beta_{6}^{\prime} X_{i t}+\delta_{t}+\gamma_{i} \text {, }
\end{aligned}
$$

where $y_{i t}$ is the outcome variable (such as publications, or forward citations, or NIH R01 grants) for scientist $i$ in year $t, W O M A N$ is a gender indicator variable, STOCK_PUBS is the cumulative number of publications for scientist $i$ up to year $t-1, F R A C S E L F$ is the proportion of all references in the articles published by scientist $i$ up to year $t-1$ that are self-references, $X$ corresponds to a vector of control covariates (degree, investigator age and its square, etc.), and $\delta_{t}$ denotes a full suite of year effects. In most cases, we transform the outcome using the inverse hyperbolic sine transformation to accommodate the large number of zero observations (Burbidge, Magee, and Robb 1988) while maintaining the ability to interpret the magnitude of coefficient estimates as elasticities (Bellemare and Wichman 2020). Specification $2 b$ includes scientist-level fixed effects $\gamma_{i}$, which will absorb the main effect of gender.

We also want to shed light on whether self-reference behavior shapes scientific careers at the extensive margin, that is, whether it influences the decision to exit science, or patterns of transition from stable careers (where scientists control the direction of their investigations) to marginal positions (where they have much less autonomy). Estimating the determinants of exit requires a statistical framework that accommodates the discrete nature of the event. Using the cross-section of 3,667 scientists (with covariates set at their terminal value-the year of exit or the year of censoring, whichever comes earlier), we employ discrete-time hazard rate models (Myers, Hankey, and Mantel 1973; Allison 1982). The use of discrete-time models (as opposed to continuous-time models such as Cox's) is motivated by the lumpiness of the failure time information in our data: we observe exit only at an annual frequency, which results in the heaping of failure times. We use a logistic regression function to link the hazard rate with time and the explanatory covariates. In practice, we estimate a simple logit of the "decision" to transition out of academia or stable employment, where the observations corresponding to years 
subsequent to the mobility event have been dropped from the estimation sample (see Azoulay, Ganguli, and Graff Zivin [2017] for an example of the same technique used to analyze mobility patterns in a sample of elite scientists). ${ }^{9}$

\section{Results}

Table 3 presents the results of the analysis of self-reference at the citing-cited article pair level. Columns 1, 2, and 3 include only one effect of interest, that of the gender indicator variable. Column 1 includes a relatively parsimonious set of fixed effects (e.g., publication years for citing and cited articles, etc.); column 2 adds a comprehensive set of fixed effects for 3,031 journals; and column 3 corresponds to our most saturated model, also including 99 dummies corresponding to the percentile of the distribution of long-run forward citations for the citing articles, ${ }^{10}$ implicitly comparing self-reference behavior holding "scientific fertility" constant. ${ }^{11}$

Across columns, the gender effect is negative and statistically significant, consistent with prior research. Its magnitude is rather tiny, however, corresponding to between 3 and 4 percent of the standard deviation of the outcome. Column 4 adds to the covariates included in column 3 our indicator of intellectual relatedness between citing and cited articles (i.e., the two articles are intellectual neighbors according to PMRA). The effect is both large in magnitude and precisely estimated, but interestingly does not affect the coefficient estimate for the gender effect.

Column 5 adds to the specification with the count of citable items published to date by the focal scientist, in logged form. As in the results presented by Mishra et al. (2018), the effect of gender disappears in these specifications-a precisely estimated zero. Column 6 augments the specification with an interaction term between gender and the stock of citable items. The gender effect remains very small in magnitude and is only marginally significant. Across their entire career, men and women scientists in our sample do not differ much in their relative propensity to reference their own work, and they appear not to differ at all after one adjusts the effect for the opportunity to self-cite.

Figure 3 and Table 4 leverage the longitudinal structure of our data set to explore the stability of the gender effect over calendar time, career stage, and career type. We begin by estimating the specification in Table 5, column 5 on 26 subsamples corresponding to all the publication years for citing articles between 1970 and 2005. We then graph each coefficient estimate for the gender effect in Figure 3, Panel A. Although the effects in the early years appear less precisely estimated (recall that relatively few scientists contribute articles during these years), the picture that emerges is one of "precisely estimated zeros" throughout the period: the "gender non-effect" is stable over time.

The next step is to break down the overall data set into subsample corresponding to different career stages: graduate school, postdoctoral phase, the first five years of the "independent" (i.e., post-training) career, years 5 through 10, 10 through 15, and so on in five-year increments, with a last category absorbing career years 30 and later for the scientists who reached this "advanced" career age. Figure 3, Panel B displays the coefficient estimates for the gender effect (the underlying specification corresponds as above to that displayed in column 5 of Table 3 ). We find evidence of 


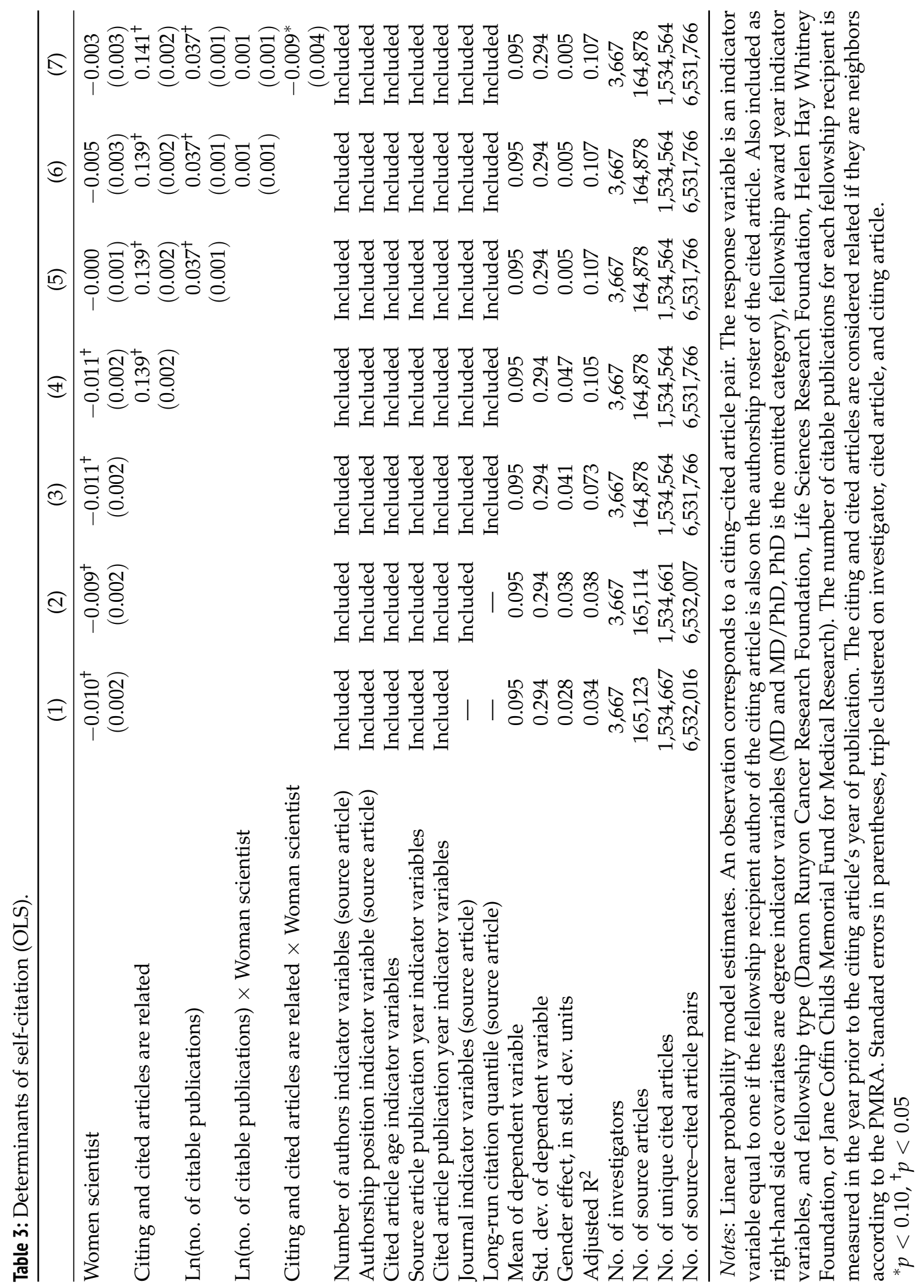




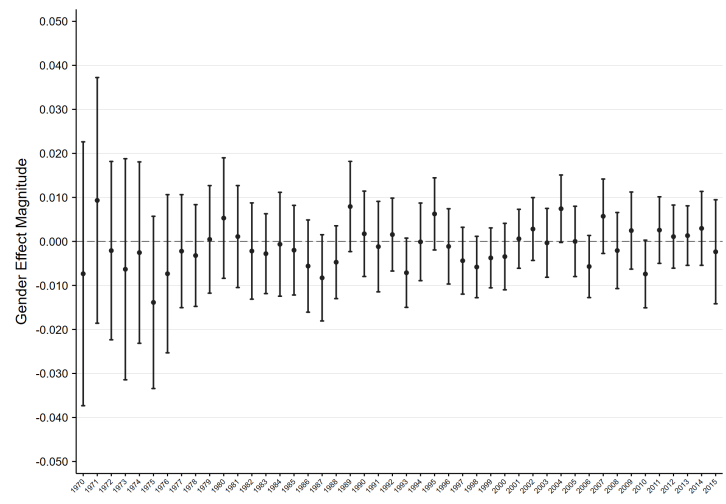

(a) Calendar year splits.

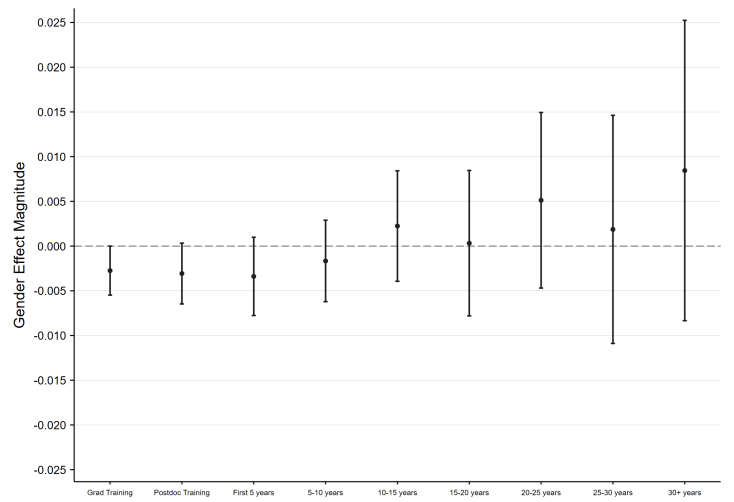

(b) Career sequence splits.

Figure 3: Gender effect magnitudes. Notes: Panel A displays coefficient estimates (and associated 95 percent confidence intervals) for the gender effects in 26 distinct regressions modeled after the specification in Table 4 , column 5. Each regression is run on a subsample that only includes source publications that appeared during a specific year, from 1970 to 2015. Panel B proceeds in the same spirit but breaks down the data into nine subsamples corresponding to natural career intervals: graduate school, postdoctoral fellowship(s), first five years post-training, years 5 to $10, \ldots$, years 25 to 20 , and finally beyond the 30 th year of career.

a negative and statistically significant gender effect in the very early career, which becomes undistinguishable from zero at the five-year post-training mark. Though more precisely estimated early on, the effect's magnitude is trivial.

Finally, Table 4 breaks apart the sample by initial post-training sorting patterns into different types of jobs: fellows who start in a standard tenure-track type academic position, fellows who join a biopharmaceutical firm after completion of their training, and fellows who convert their training into a "marginal" academic position, that is, full-time "research associate" in an another scientist's lab, adjunct teaching, and so on. A final category includes all scientists who pursue research after training, regardless of setting (academia or industry). For each type of initial position, we compare two sets of estimates, the first based on the specification in Table 3, column 4-which does not control for the stock of citable items-the second based on the specification in Table 3, column 5-which does. As in Table 3, we typically find precisely estimated, negative gender effects of very modest magnitudes without controlling for citing opportunities, which completely disappear once these opportunities are controlled for.

From all these analyses at the citing-cited article pair level, we conclude that men and women scientists do not appear to differ much in their propensity to self-cite, especially when focusing on self-references per unit of past productivity. Moreover, these equal propensities exhibit striking stability across time, type of initial position, and career stage. 


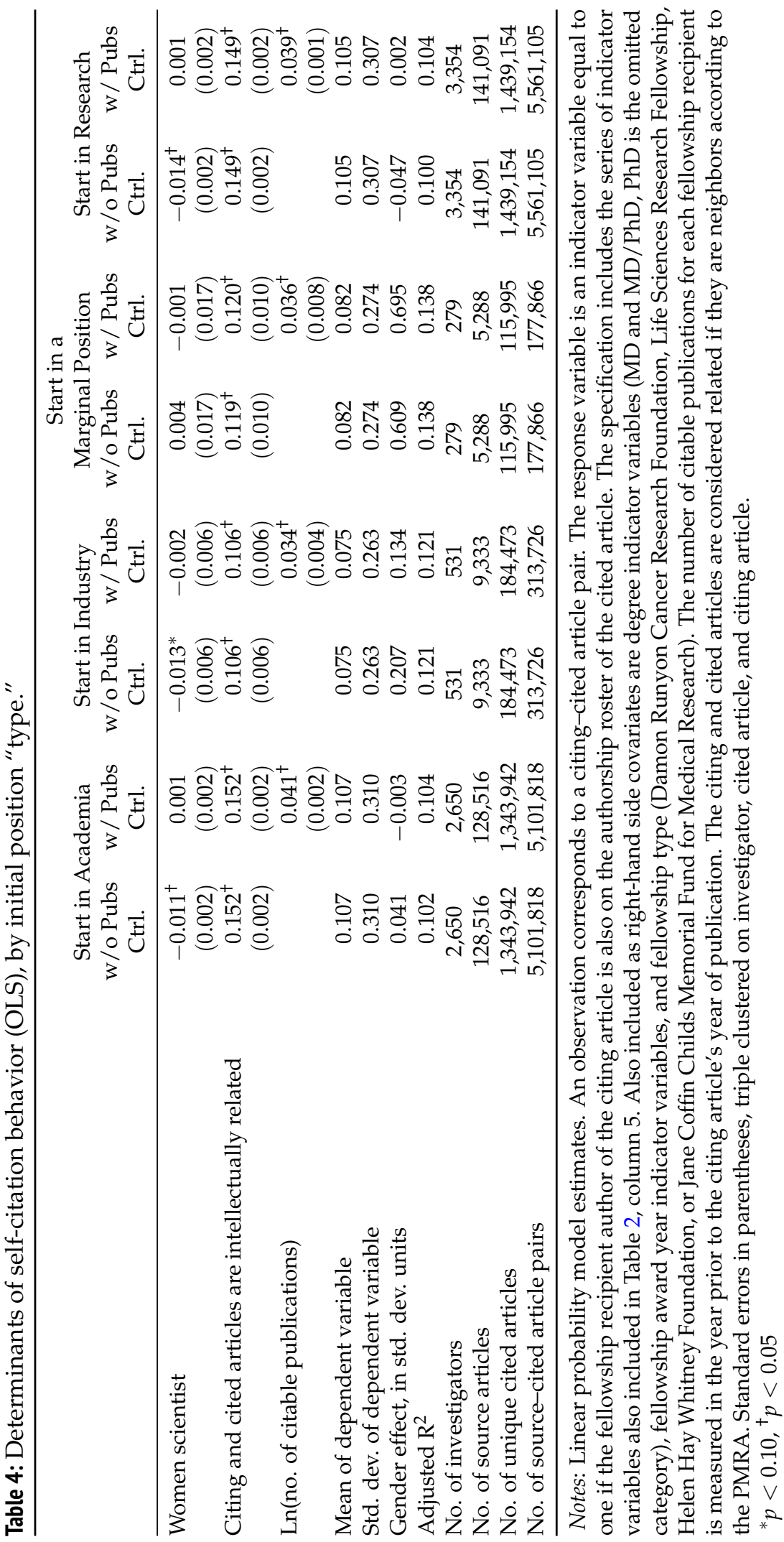




\section{From Self-Citation to Self-Promotion}

The above exercise is informative with respect to the debate regarding disparities in self-promotional behavior across genders only to the extent that self-reference is accepted as a proxy for self-aggrandizement. Although this is a natural first step, below we seek to distinguish between "gratuitous" and "legitimate" self-referencing behavior by attending to the intellectual closeness between each citing and cited article. Recall that from columns 4, 5, and 6 in Table 3, we already established that the scientists in our sample are more likely to self-reference an intellectually related article than an unrelated one. In column 7 of Table 3, we augment the specification with an interaction term between relatedness and gender. A positive coefficient for this covariate would support the claim that, although men and women scientists self-cite at similar rates, men scientists are less reluctant to do so in situations where the connection between the two pieces of research is intellectually tenuous.

We do not find evidence for this claim. If anything, we find that women scientists appear slightly more likely to self-reference unrelated work than men. However, the magnitude of the effect is extremely modest (about 5 percent of the magnitude for the main effect of relatedness). Figure 4 pushes this analysis further. Intellectual relatedness exists on a spectrum, a fact recognized by the PMRA. For any source article, PMRA returns a ranked list of intellectual neighbors (the cutoff rules for PMRA are explored at length in Azoulay, Whalen, and Zuckerman Sivan [2019], Appendix C). Every citation link in our data set can correspond to a particular relatedness rank, from completely unrelated (80.0 percent of the sample) to relatedness rank $1,2,3, \ldots$ until about 10,000 . We create 111 gender by relatedness rank interaction effects, which we include in the specification (the main effects of gender and the relatedness dummies are of course included as well). Figure 4 displays the coefficient estimates for these interaction terms. Although the majority have a negative sign, they are invariably small in magnitude, and it is hard to discern any monotonic trend in the effect. From these analyses, we conclude that men and women do not differ in their propensity to self-cite gratuitously, any more than they differ in their overall self-reference propensity. ${ }^{12}$

\section{Returns to Self-References}

We conclude the study by examining whether scientists can parlay self-references into future productivity and career rewards and whether the returns to self-reference differ across genders. To do so, we shift the level of analysis away from the citingcited article pair to the individual scientist. A necessary note of caution is that we do not have at our disposal exogenous shifters of the propensity to self-cite. As such, the effects we estimate below could suffer from omitted variable bias-they correspond to conditional correlations, not causal effects.

Table 5 focuses on the forward citation returns to self-referencing behavior. The dependent variable in all specifications is the inverse hyperbolic sine of the flow of citations received to the articles published up to the current year by each scientist, purged of self-citations. All independent variables are lagged one year. As seen in Equations (2a) and (2b) above, all specifications include a full suite of calendar year 


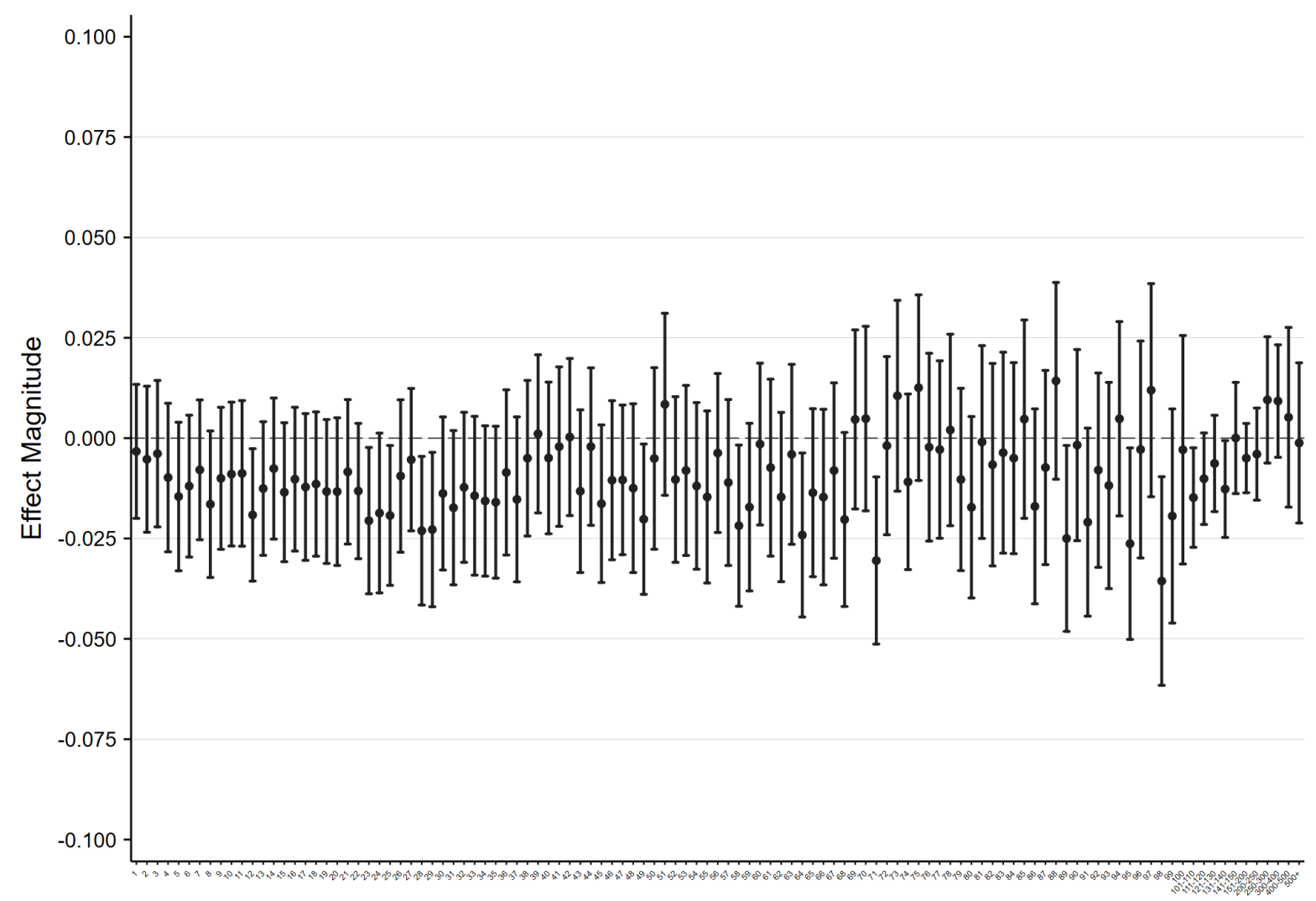

Figure 4: Gender $\times$ relatedness rank interactions. Notes: Figure 3 displays the coefficient estimates (and associated 95 percent confidence intervals) for the interaction effects between gender and relatedness rank in an expanded version of the specification appearing in Table 3, column 7. In these specifications, relatedness is broken down into 112 dummies: PMRA unrelated (the omitted category), PMRA related of rank 1, PMRA related of rank 2, ... PMRA related of rank 100, 100 to 110, 110 to 120,120 to 130, 130 to 140,140 to 150, 150 to 200,201 to 250,251 to 300,301 to 400,401 to 500 , and finally 501 to 10,000. These main effects of intellectual relatedness are further interacted with gender.

effects. The models are estimated by OLS, and standard errors are clustered at the level of the scientist in all cases.

The first model (column 1) estimates the gender gap in forward citations (purged of self-citations) in the sample, net of cohort effects (eight indicator variables corresponding to years of highest degree, in five-year increments), a full suite of calendar year effects, and age effects (the investigator's career age and its square). The results imply that women scientists accumulate about 5 percent less citations than men every year, on average.

The remaining specifications are presented in pairs, the first corresponding to the pooled cross-section, whereas the second includes scientist fixed effects, which cause the main effect of gender to drop out. 


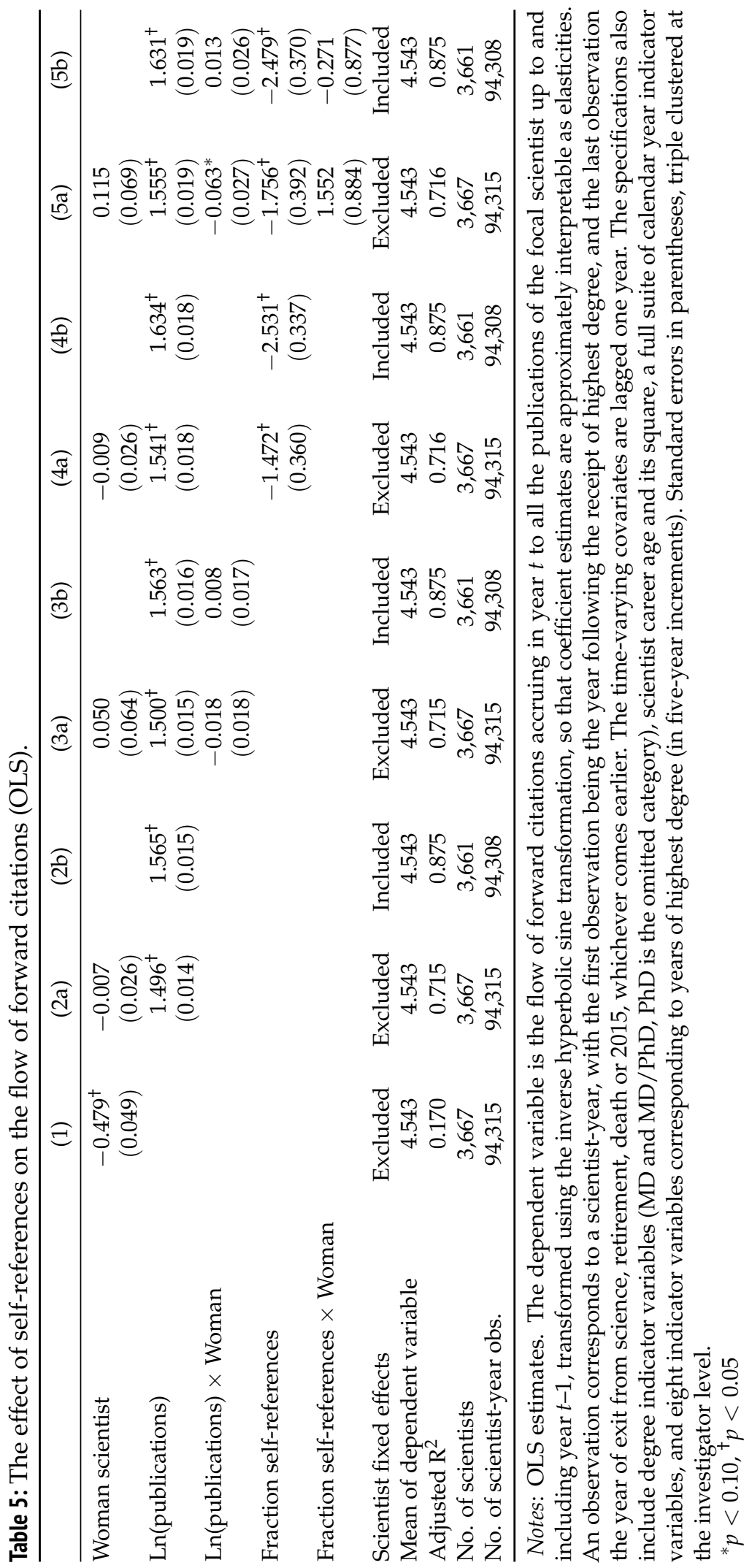


From column 2a, after controlling for the stock of publications (lagged one year), the evidence of gender disparity in citations vanishes. An additional publication is associated with about 1.5 forward citations on average, or slightly lower (1.3) in the within-scientist dimension of the data (in column $2 \mathrm{~b}$ ). Columns $3 \mathrm{a}$ and $3 \mathrm{~b}$ also demonstrate the absence of gender disparities in the ability to covert publications into future citations. Columns $4 \mathrm{a}$ and $4 \mathrm{~b}$ include the proportion of self-references in the body of work of the investigator to date. Interestingly, scientists appear to suffer a penalty, not a discount, for self-promotional behavior, although it is of small magnitude. At the mean of the data, the estimate in column 4a implies that an additional 1 percent in the fraction of self-references (roughly a 20 percent increase) is associated with a 0.08 percent decrease in the number of forward citations. The estimate is twice as large in column $4 \mathrm{~b}$-the implied elasticity is 0.145 - but this remains a relatively modest effect. Finally, columns $5 \mathrm{a}$ and $5 \mathrm{~b}$ introduce an interaction effect between gender and the proportion of self-references in past work. The estimate in column 5 a is positive in statistically significant, indicating that relative to men, women earn a citation return on self-referencing behavior. However, computing the implied elasticities using the delta method leads to the conclusion that this differential effect is small: whereas men lose one forward citation on average for a 1 percent increase in the fraction of self-references, women scientists lose "only" 0.8 citations. Furthermore, the differences between men and women vanish altogether when adding scientist fixed effects to the specification (column $5 b) .{ }^{13}$

Table 6 provides an analysis in the same spirit but focusing on career transitions rather than scientific output. We do not discuss these results in the same amount of detail because they paint a similar picture. The first batch of columns reports discrete-time hazard estimates (with a logit link function) in the cross-section corresponding to the last year before exit from academia or 2015, whichever comes earlier. Here we do find evidence of a small gender gap, with women scientists about 5 percent more likely than men to leave academia (column 1a). But the effect's sign is reversed after controlling for the publication stock (column 1b): women scientists are now 5 percent less likely than men to leave academia. Unsurprisingly, lower amounts of publications contribute to an elevated risk of transitioning out, but this appears equally true for men and women (column 1c). Self-referencing behavior appears associated with a slightly higher probability of exit (column 1d), but not differentially so for men and women (column 1e).

The second batch of four columns defines career exit differently, by focusing on the "marginality" of the position. This is somewhat arbitrary, but our coding attempts to capture the timing of entry into a phase of the career when the scientist would lose his or her scientific autonomy. In practice, a tenure-track academic, a venture capitalist, a patent lawyer, and an industry scientist all have a stable position using this coding, whereas a lab technician, an adjunct faculty member, a medical professional (with purely clinical duties), or a high school science teacher all have marginal positions. Here we do find evidence that women scientists are more likely to exit (column 2a), but the effect is quite small in magnitude once past publication output is added as a covariate (column $2 b$ ). We also find evidence of a 


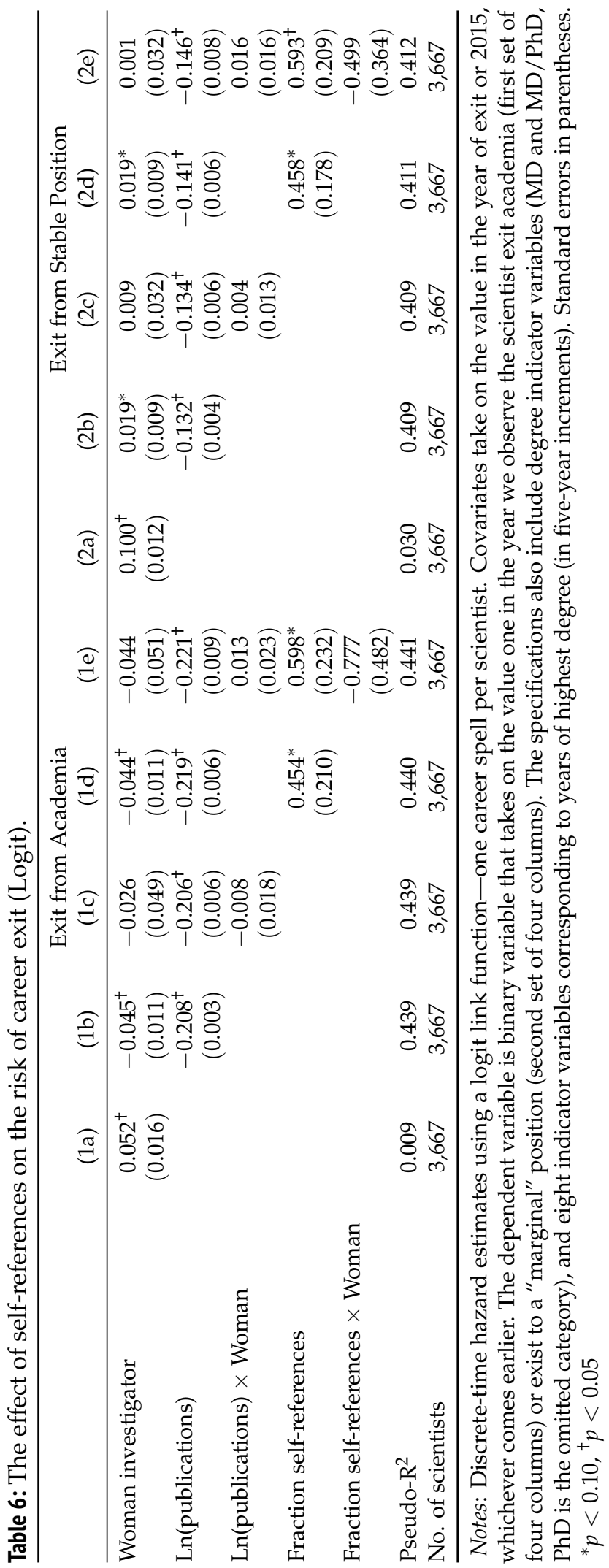


positive association between rates of self-referencing and exit, but again it does not differ along gender lines (columns $2 \mathrm{c}$ and $2 \mathrm{~d}$ ).

To summarize, we find no support for the notion that the long-term impact of self-referencing is more positive for men than for women. In fact, we find that aggressive self-referencing, as operationalized by fraction of total backward references to self, is not even positively correlated with "good" career outcomes, such as future citations and career stability. The lesson here is that, contrary to initial expectations, neither Pierre nor Pierrette should expect their self-referencing behavior to generate a boost to their long-term visibility.

\section{Discussion}

Considering the results in their totality, we feel confident in stating that, in our sample at least, men and women scientists do not meaningfully differ in their propensity to self-reference once the stock of citable publications is taken into account. This aligns with the declaration by Mishra et al. (2018) that self-references are simply the "hallmark of productive authors." Importantly, our analyses can further show that this conclusion holds even when focusing on self-citations of intellectually unrelated articles-the type of self-citation most likely to reflect selfaggrandizement instead of cumulativeness. Finally, we find no evidence of a differential ability to convert self-citations into favorable outcomes across men and women. In fact, contrary to the popular view that self-citations are an important self-marketing tool, both genders-in the long game-appear to be penalized rather than rewarded for self-referencing behavior, although the magnitude of the penalty is modest.

Of course, we had expected, extrapolating from previous literature on gender and self-promotion and self-assessment, that women scientists compared with men would self-reference less, self-reference less gratuitously, and net less for their promotional efforts. Our evidence, therefore, supports none of these hypotheses. Instead, we find no systematic gap-statistical or practical-between men and women in our sample with respect to self-reference practices or returns. So, where does this leave us?

First, it is important to note that although our results do contradict our expectations regarding self-referencing behavior, they cannot be used to adjudicate whether men and women differentially self-promote, which is clearly a much broader statement about human agency. We were motivated to study self-citation because of the literature on gender and self-promotion, but our empirical study only assesses the behavioral act of self-referencing. For example, it could be that men are indeed more aggressive self-promoters than women in science (see Lerchenmueller et al. [2019]) but that the act of self-citing is not interpreted by most scientists as particularly promotional. Researchers often regard self-referencing as a form of bragging, but it could be that self-referencing "on the ground" is merely the byproduct of satisficing, such as when authors search their own personal "garbage cans" (Cohen, March, and Olsen 1972) for a passable or plausible reference in an effort to work efficiently. In a similar vein, it could be that self-citing is broadly understood as promotional 
work but that doing so is hardly sanctioned in practice because (1) the behavior is so common and/or (2) the opportunities to sanction are few.

Second, a likely and fair response to this study is to question whether a sample of only life scientists-all of whom received a prestigious postdoctoral award-is too narrow to draw broad conclusions about how gender operates in science. We agree that that this sample has clear limits in terms of its generalizability to all fields and to all strata of authors. At the same time, our sample and results offer an important building block with regard to empirical knowledge. That is, our sample may be limited in its generalizability, but the results themselves can be clearly interpreted because we have controlled extensively for supply-side factors. As noted earlier, we are relatively confident that each cohort of young scholars in our data set is viewed by their discipline as having a great deal of potential to contribute to the field. So, within this controlled group of scholars, to what extent does gender matter for how careers unfold over time? Another building block then would be replicating this study with, say, the group of scientists who applied for but did not receive a postdoctoral award, or perhaps with a group of newly minted PhDs from a particular field but from institutions in the lower versus upper half of area-specific rankings.

The beauty of this type of research design, as Delecourt and $\mathrm{Ng}$ (2020) illustrate well, is the clarity that comes from controlling supply-side factors and, hence, isolating demand-side factors. Although we cannot completely "fix" supply-side factors as Delecourt and $\mathrm{Ng}$ (2020) are able to do with a field experiment, we come far closer to doing so compared with the many publication "snapshot" studies devoid of (or with very limited) data on career context. More specifically, we come far closer to being able to claim that women and men are rewarded differentially (or not) when they do the same thing. In this way, our conclusions not only spotlightby way of replicability-previous findings based on publication-based samples, including Mishra et al. (2018) on the null gender gap in self-citations, Lynn et al. (2019) on the null gender gap in citations per publication, and West et al. (2013) on the major gender gap in publications, but go one step further and clarify that these conclusions hold when subjected to an even stronger apples-to-apples test.

Moreover, in analyses not shown but available upon request, we also partially replicated Lerchenmueller and Sorenson's (2018) analysis of the gender gap in the timing of the first R01 grant, which is based on a sample of roughly 6,300 life scientists who won an NIH F32 National Research Service Award and produced at least one publication during the award period. They find that women F32 winners take 12 percent longer before winning an R01, and this gap cannot be explained away by accounting for publications. In our sample, we, too, find a statistically significant gap ( $\mathrm{N}=55,741$ person-years) in R01 timing, but the magnitude of our gap is miniscule. And, returning to the bigger picture (see Table A3 in the online supplement), we find no gender gap in receipt of R01 funding after accounting for stock of previous publications.

With this in mind, we see our null gender results as making an important contribution to the current conversation around gender inequality in science. To recap, our objective was to examine self-referencing in the context of scientific careers, which is why we analyzed the coevolution of publications, self-references, 
forward citations, grants, and employment type. In doing so, our results easily reveal the arc of scientific careers: regardless of gender, scientists who publish more articles earlier are more likely later to self-reference, attract citations from others, produce future publications, win grants, persist in academia, and persist in jobs with scientific autonomy. Put differently, self-citation is indeed a hallmark of productivity, but so is every reward in science.

What is noteworthy then about these results is that, even though the conversion of earlier publications into later rewards is not gendered, there is an inexplicable gender gap in publications that begins in the very first career period for which scientists are tracked (graduate school) and persists through every career stage thereafter (see Figure 1). Observation one is thus the unusually good news that women's and men's careers tend to unfold in highly similar ways when they publish at the same rate. Observation two, however, is that even among a sample of the most competitive graduate students in life sciences, women and men are not publishing at the same rate, and so amass fewer rewards over the career course. In sum, for this sample of scientists, the publication process is the single source of fuel for gender divergence in career trajectories.

Although some might interpret this as arriving back at square one, that is, the "old puzzle" that is the gender gap in publications (Xie and Shauman 1998), we find our results provocative because of the sample of elite graduate students on which they are based. Again, this is because supply-side explanations have been effectively ruled out with this sample. For example, variation in human capital and training experience is tightly controlled in our data given that we selected only high-achieving graduate students recognized by field leaders for their potential to contribute. Regarding individual tastes and preferences, we know that all in our sample were motivated enough to apply for prestigious postdoctoral positions and that all chose to throw their proverbial hat in the ring by accepting. We also know that scientists in the sample worked primarily in academic research jobs. Thus, the persistent gender gap in publications we observe here cannot be a byproduct of the job requirements associated with teaching versus research track positions, which has been shown to explain the publication gender gap in data sets based on broader samples of scholars (Xie and Shauman 2003).

Being able to reasonably set aside these major explanations means that we can approach the productivity gap with renewed focus. Not only is the productivity gap the puzzle to solve, we now know that (1) a publication gap can persist between men and women even in the absence of any major differences in human capital, motivation, or job requirements, and (2) whatever mechanism(s) creating the gender gap in publications are somehow muted when it comes to publications being converted into future rewards. For example, in order to assert that demand-side discrimination (e.g., the brilliance penalty) is the key reason why women publish less than men, one would also have to explain why this mechanism has a negligible effect on how women and men accrue citations and grants controlling for the publications they produce.

One promising line of work digs into the beast that is the journal peer review process, a specific type of multistaged, gatekeeping system that applies to the process of publishing articles (and sometimes books). Although there is little 
evidence to suggest that editors are more likely to accept manuscripts written by men compared with women (e.g., Borsuk et al. 2009; Blank 1991), there is compelling evidence to suggest that women on average generate higher quality work during the peer review process (Hengel 2017), in part because reviewers and editors appear to impose higher standards on women (Card et al. 2020). ${ }^{14}$ Ultimately, this process could push women to "spend too much time rewriting old papers and not enough time writing new papers" (Hengel 2017:3). Although our own data unfortunately cannot be leveraged to investigate this proposition or peer review experiences more generally, we can perhaps motivate women scientists, as well as future research on the gendered costs of publishing, by showing that on the other side of this bottleneck, women and men earn roughly the same recognition per publication.

\section{Notes}

1 See also Franck (1999) on "citation cartels."

2 For a handful of fellows in the most recent cohorts who had not started an independent career as of 2015, we track their institutional affiliations again in early 2020. By that time, every individual in the sample had either completed training or exited science.

3 Throughout the data and results sections, we use the term self-reference rather than self-citation to underscore that our analyses pertain to reference lists within publications (backward or outgoing references to previously published works) and not citations accruing to publications (incoming references), which we refer to below as forward citations.

4 The longitudinal structure of the data will allow us to attend to calendar time effects separately from cohort effects below (this is true in general, but for publication rates in particular, see Table A4 in the online supplement).

5 The "other industry" category denotes positions in a variety of pursuits unrelated to education or research in the life sciences, typically in industrial firms, but also including two individuals serving time in a federal penitentiary, a paramedic fireman, a cheesemaker, as well as a "shamanic practitioner and sacred artist."

6 To facilitate the harvesting of intellectually related records on a large scale, we have developed an open-source software tool that queries PubMed and PMRA and stores the retrieved data in a MySQL database. The software is available for download at http:/ /www.stellman-greene.com/FindRelated/. Appendix C in Azoulay, Whalen, and Zuckerman Sivan (2019) provides much more detail on the algorithm and its use.

7 The rich contextual information about the identities of these scientists allows us to detect that three of them had changed gender midcareer. In the analyses below, these trans-identified individuals are coded as their sex assigned at birth. In addition, because our data set is based on detailed dossiers of individual scientists, we also identified 89 individuals in the sample (2.42 percent) who changed their names or published under different names over the course of their careers. The majority of name changers are women (86.52 percent).

8 For instance, cumulativeness is important in science, and one would expect researchers who specialize and consolidate lines of research, which we refer to as "hedgehog" researchers (Berlin 1953), to self-reference more often relative to "fox" researchers who have more diverse interests (Leahey 2006, 2007). 
9 We use quotes around the word decision because, although some of these transitions might be voluntary (such as leaving academia for industry in quest of a new challenge or more tangible "impact"), many will not be (such as falling out of the tenure track after losing in NIH funding competition). Our coding of stable versus marginal positions is motivated in part by this distinction, because few scientists would prefer them over less precarious (and more prestigious) positions.

10 These distributions are vintage-specific (allowing us to compare the citation impact of articles published in different years) and are based on citation counts that exclude (forward) self-citations.

11 Specifically, columns 3 through 7 include a total of 107,726 indicator variables to estimate the gap in self-citation behavior.

12 In the present article, the number of self-references by the male coauthor is three, versus only one for the female coauthor. We leave it as an exercise for the reader to figure out whether this disparity reflects self-aggrandizement on the part of one member of our mixed-gender team, a tragic lack of self-awareness on the part of both coauthors, or something more benign.

13 Tables A3 and A4 in the online supplement reproduce this analysis using two additional outcomes: receipt of an R01 grant from the National Institute of Health, and number of publications. The magnitudes differ, but the qualitative conclusions of the analysis above remain unchanged.

14 Hengel's (2017) analyses, too, suggest that women engage in more work in the peer review process more so because editors and reviewers implicitly set the bar higher for women and less so because of supply-side differences in, say, how authors respond to negative reviews.

\section{References}

Aksnes, Dag W. 2003. “A Macro Study of Self-Citation.” Scientometrics 56(2):235-46. https : //doi.org/10.1023/A:1021919228368.

Allison, Paul D., 1982. "Discrete-Time Methods for the Analysis of Event Histories." Pp. 61-98 in Sociological Methodology, edited by Samuel Leinhardt. San Francisco, CA: JosseyBass.

Angrist, Joshua D., and Jörn-Steffen Pischke. 2008. Mostly Harmless Econometrics: An Empiricist's Companion. Princeton, NJ: Princeton University Press. https ://doi .org/10.1515/ 9781400829828.

Auster, Carol J., and Susan C. Ohm. 2000. "Masculinity and Femininity in Contemporary American Society: A Reevaluation Using the Bem Sex-Role Inventory." Sex Roles 43(7):499528. https://doi.org/10.1023/A:1007119516728.

Azoulay, Pierre, Christian Fons-Rosen, and Joshua S. Graff Zivin. 2019. "Does Science Advance One Funeral at a Time?" American Economic Review 109(8):2889-920. https : //doi.org/10.1257/aer. 20161574.

Azoulay, Pierre, Ina Ganguli, and Joshua Graff Zivin. 2017. “The Mobility of Elite Life Scientists: Professional and Personal Determinants." Research Policy 46(3):573-90. https : //doi.org/10.1016/j.respol.2017.01.002.

Azoulay, Pierre, J. Michael Whalen, and Ezra W. Zuckerman Sivan. 2019. "Death of the Salesman, But not the Sales Force: How Interested Promotion Skews Scientific Valuation." American Journal of Sociology 125(3):786-845. https : //doi .org/10.1086/706800. 
Bellemare, Marc F., and Casey J. Wichman. 2020. "Elasticities and the Inverse Hyperbolic Sine Transformation." Oxford Bulletin of Economics and Statistics 82(1):50-61. https: //doi.org/10.1111/obes. 12325.

Berlin, Isaiah. 1953. The Hedgehog and the Fox: An Essay on Tolstoy's View of History. London: Weidenfeld \& Nicolson.

Bian, Lin, Sarah-Jane Leslie, and Andrei Cimpian. 2017. “Gender Stereotypes about Intellectual Ability Emerge Early and Influence Children's Interests." Science 355(6323):389-91. https://doi.org/10.1126/science. aah6524.

Blank, Rebecca M. 1991. “The Effects of Double-Blind versus Single-Blind Reviewing: Experimental Evidence from The American Economic Review." American Economic Review 81(5):1041-67.

Bonzi, Susan, and Herbert Snyder. 1991. "Motivations for Citation: A Comparison of SelfCitation and Citations to Others." Scientometrics 21(2):245-54. https://doi .org/10. $1007 /$ BF02017571.

Borsuk, Robyn M., Lonnie W. Aarssen, Amber E. Budden, Julia Koricheva, Roosa Leimu, Tom Tregenza, and Christopher J. Lortie. 2009. "To Name or Not to Name: The Effect of Changing Author Gender on Peer Review." BioScience 59(11):985-89. https : //doi .org/ 10.1525/bio.2009.59.11.10.

Burbidge, John B., Lonnie Magee, and A. Leslie Robb. 1988. “Alternative Transformations to Handle Extreme Values of the Dependent Variable." Journal of the American Statistical Association 83(401):123-27. https://doi .org/10.1080/01621459.1988.10478575.

Card, David, Stefano DellaVigna, Patricia Funk, and Nagore Iriberri. 2020. "Are Referees and Editors in Economics Gender Neutral?" Quarterly Journal of Economics 135(1):269-327. https://doi.org/10.1093/qje/qjz035.

Cohen, Michael D., James G. March, and Johan P. Olsen. 1972. “A Garbage Can Model of Organizational Choice." Administrative Science Quarterly 17(1):1-25. https : //doi .org/ $10.2307 / 2392088$.

Correll, Shelley J. 2001. "Gender and the Career Choice Process: The Role of Biased SelfAssessments." American Journal of Sociology 106(6):1691-730. https : //doi .org/10.1086/ 321299.

Correll, Shelley J. 2004. "Constraints into Preferences: Gender, Status, and Emerging Career Aspiration." American Sociological Review 69(1):93-113. https://doi .org/10.1177/ 000312240406900106.

Delecourt, Solène, and Odyssia Ng. 2020. “Do Buyers Discriminate against Female-Owned Businesses? Two Field Experiments." Working Paper, Stanford University.

DiPrete, Thomas A., and Gregory M. Eirich. 2006. "Cumulative Advantage as a Mechanism for Inequality: A Review of Theoretical and Empirical Developments." Annual Review of Sociology 32(1):271-97. https://doi .org/10.1146/annurev . soc.32.061604.123127.

Eagly, Alice H., and Steven J. Karau. 2002. "Role Congruity Theory of Prejudice toward Female Leaders." Psychological Review 109(3):573-98. https://doi.org/10.1037/ 0033-295X . 109.3.573.

Exley, Christine L, and Judd B. Kessler. 2019. “The Gender Gap in Self-Promotion.” Working Paper 26345. National Bureau of Economic Research. https://doi.org/10.3386/ w26345.

Fiske, Peter. 2018. "Boost Your Market Value." Nature 555(8):275-76. https: //doi .org/10. 1038/d41586-018-02747-y. 
Fowler, James H., and Dag W. Aksnes. 2007. "Does Self-Citation Pay?" Scientometrics 72:427-37. https://doi.org/10.1007/s11192-007-1777-2.

Franck, Georg. 1999. “Scientific Communication-A Vanity Fair?” Science 286(5437):53. https://doi.org/10.1126/science.286.5437.53.

Garfield, Eugene. 1987a. "Some Deviant Behavior in Science Has Nothing at All to Do with Fraud." Current Contents 49:370-72.

Garfield, Eugene. 1987b. "Is There Room in Science for Self-Promotion?" Scientist, December 14. Retrieved October 5, 2019, https://www.the-scientist.com/opinion-old/ is-there-room-in-science-for-self-promotion-3274.

Ginther, Donna K., and Misty L. Heggeness. 2020. “Administrative Discretion in Scientific Funding: Evidence from a Prestigious Postdoctoral Training Program." Research Policy 49(4):103953. https://doi.org/10.1016/j.respol.2020.103953.

Hengel, Erin. 2017. "Publishing while Female. Are Women Held to Higher Standards? Evidence from Peer Review," Cambridge Working Papers in Economics 1753, Faculty of Economics, University of Cambridge.

Hill, Ryan Reed. 2018. "Searching for Superstars: Research Risk and Talent Discovery in Astronomy." Working Paper, MIT.

Hyland, Ken. 2003. "Self-Citation and Self-Reference: Credibility and Promotion in Academic Publication." Journal of the American Society for Information Science and Technology 54(3):25159. https://doi.org/10.1002/asi.10204.

Ioannidis, John P. A. 2015. “A Generalized View of Self-Citation: Direct, Co-Author, Collaborative, and Coercive Induced Self-Citation." Journal of Psychosomatic Research 78(1):7-11. https://doi.org/10.1016/j.jpsychores.2014.11.008.

Ioannidis, John P. A., Althina Tatsioni, and Fotini B. Karassa. 2010. “Who's Afraid of Reviewers' Comments? Or, Why Anything Can Be Published and Anything Can Be Cited." European Journal of Clinical Investigation 40(4):285-87. https : //doi . org/10.1111/ j.1365-2362.2010.02272.x.

King, Molly M., Carl T. Bergstrom, Shelley J. Correll, Jennifer Jacquet, and Jevin D. West. 2017. "Men Set Their Own Cites High: Gender and Self-Citation across Fields and over Time." Socius, first published on December 8, https : //doi .org/10.1177/2378023117738903.

Koenig, Anne M. 2018. "Comparing Prescriptive and Descriptive Gender Stereotypes about Children, Adults, and the Elderly." Frontiers in Psychology 9:1086. https ://doi .org/10 . 3389/fpsyg. 2018.01086.

Lawani, Stephen M. 1982. "On the Heterogeneity and Classification of Author Self-Citations." Journal of the American Society for Information Science 33(5):280-84. https : //doi . org/10 . 1002/asi.4630330506.

Lerchenmueller, Marc J., and Olav Sorenson. 2018. “The Gender Gap in Early Career Transitions in the Life Sciences." Research Policy 47(6):1007-17. https://doi .org/10. 1016/j.respol.2018.02.009.

Lerchenmueller, Marc J., Olav Sorenson, and Anupam B. Jena. 2019. “Gender Differences in How Scientists Present the Importance of Their Research: Observational Study." British Medical Journal 367:16573. https://doi .org/10.1136/bmj . 16573.

Leahey, Erin. 2006. “Gender Differences in Productivity: Research Specialization as a Missing Link." Gender E Society 20(6):754-80. https ://doi .org/10.1177/0891243206293030.

Leahey, Erin. 2007. "Not by Productivity Alone: How Visibility and Specialization Contribute to Academic Earnings." American Sociological Review 72(4):533-61. https : //doi . org/10 . $1177 / 000312240707200403$. 
Leslie, Sarah-Jane, Andrei Cimpian, Meredith Meyer, and Edward Freeland. 2015. "Expectations of Brilliance Underlie Gender Distributions across Academic Disciplines." Science 347(6219):262-65. https://doi.org/10.1126/science.1261375.

Levitt, David G. 2010. “Careers of An Elite Cohort of U.S. Basic Life Science Postdoctoral Fellows and the Influence of Their Mentor's Citation Record." BMC Medical Education 10:80. https://doi.org/10.1186/1472-6920-10-80.

Lin, Jimmy, and W. John Wilbur. 2007. "PubMed Related Articles: A Probabilistic TopicBased Model for Content Similarity." BMC Bioinformatics 8(423):1-14. https : //doi .org/ 10.1186/1471-2105-8-423.

Lynn, Freda B., Mary C. Noonan, Michael Sauder, and Matthew A. Andersson. 2019. “A Rare Case of Gender Parity in Academia." Social Forces 98(2):518-47. https ://doi .org/ $10.1093 / \mathrm{sf} / \mathrm{soy} 126$.

MacRoberts, Michael H., and Barbara R. MacRoberts, 1989. "Problems of Citation Analysis: A Critical Review." Journal of the American Society for Information Science 40(5):342-49. https : //doi.org/10.1002/(SICI) 1097-4571(198909) 40:5<342: :AID-ASI7>3.0. C0;2-U.

Mantovani, Richard, Mary V. Look, and Emily Wuerker. 2006. The Career Achievements of National Research Service Award Postdoctoral Trainees and Fellows: 1975-2004. Bethesda, MD: ORC Macro.

McGinnnis, Robert, Paul D. Allison, and J. Scott Long. 1982. "Postdoctoral Training in Bioscience: Allocation and Outcomes." Social Forces 60(3):701-22. https : //doi . org/10 . $2307 / 2578388$.

Medoff, Marshall H. 2006. "The Efficiency of Self-Citations in Economics." Scientometrics 69:69-84. https://doi.org/10.1007/s11192-006-0139-4.

Merton, Robert K. [1942] 1973. “The Normative Structure of Science." In The Sociology of Science: Theoretical and Empirical Investigations, edited by Norman W. Storer. Chicago, IL: University of Chicago Press.

Mishra, Shubhanshu, Brent D. Fegley, Jana Diesner, and Vetle I. Torvik. 2018. "Self-Citation Is the Hallmark of Productive Authors, of Any Gender." PLoS One 13(9):e0195773. https://doi.org/10.1371/journal pone.0195773.

Moss-Racusin, Corinne A., John F. Dovidio, Victoria L. Brescoll, Mark J. Graham, and Jo Handelsman. 2012. "Science Faculty's Subtle Gender Biases Favor Male Students." Proceedings of the National Academy of Sciences 109(41):16474. https://doi .org/10.1073/ pnas. 1211286109.

Moss-Racusin, Corinne A., Julie E. Phelan, and Laurie A. Rudman. 2010. "When Men Break the Gender Rules: Status Incongruity and Backlash against Modest Men." Psychology of Men E Masculinity 11(2):140-51. https : //doi .org/10.1037/a0018093.

Myers, Max H., Benjamin F. Hankey, and Nathan Mantel. 1973. “A Logistic-Exponential Model for Use with Response-Time Data Involving Regressors Variables." Biometrics 29(2):257-69. https://doi .org/10.2307/2529390.

Nelkin, Dorothy. 1987. In Selling Science: How the Press Covers Science and Technology. New York, NY: W. H. Freeman.

Neyman, Jerzy, and Elizabeth L. Scott 1948. "Consistent Estimates Based on Partially Consistent Observations." Econometrica 16(1):1-32. https ://doi .org/10.2307/1914288.

Reis, Richard M. 1999. "The Need for Self-Promotion in Scientific Careers." Chronicle of Higher Education, April 23. Retrieved October 5, 2019, https://www.chronicle.com/article/ The-Need-for-Self-Promotion-in/45602. 
Reuben, Ernesto, Paola Sapienza, and Luigi Zingales. 2014. "How Stereotypes Impair Women's Careers in Science." Proceedings of the National Academy of Sciences 111(12):440308. https://doi.org/10.1073/pnas.1314788111.

Reuben, Ernesto, Pedro Rey-Biel, Paola Sapienza, and Luigi Zingales. 2012. "The Emergence of Male Leadership in Competitive Environments." Journal of Economic Behavior and Organization 83(1):111-17. https://doi .org/10.1016/j . jebo.2011.06.016.

Ridgeway, Cecilia L. 2011. Framed by Gender: How Gender Inequality Persists in the Modern World. New York, NY: Oxford University Press.

Rudman, Laurie A. 1998. "Self-Promotion as a Risk Factor for Women: The Costs and Benefits of Counter Stereotypical Impression Management." Journal of Personality and Social Psychology 74(3):629-45. https : //doi .org/10.1037/0022-3514.74.3.629.

Silva, Elizabeth A., Christine Des Jarlais, Bill Lindstaedt, Erik Rotman, and Elizabeth S. Watkins. 2016. "Tracking Career Outcomes for Postdoctoral Scholars: A Call to Action." PLoS Biology 14(5):e1002458. https ://doi .org/10.1371/journal .pbio. 1002458.

Snyder, Herbert, and Susan Bonzi. 1998. "Patterns of Self-Citation Across Disciplines (1980-1989)." Journal of Information Science 24(6):431-35. https://doi .org/10.1177/ 016555159802400606.

Tagliacozzo, Renata. 1977. "Self-Citations in Scientific Literature." Journal of Documentation 33(4):251-65. https://doi.org/10.1108/eb026644.

Thébaud, Sarah. 2015. "Status Beliefs and the Spirit of Capitalism: Accounting for Gender Biases in Entrepreneurship and Innovation." Social Forces 94(1):61-86. https://doi . org/10.1093/sf/sov042.

Thombs, Brett D., Alexander W. Levis, Ilya Razykov, Achyuth Syamchandra, Albert F. G. Leentjens, James L. Levenson, and Mark A. Lumley. 2015. "Potentially Coercive SelfCitation by Peer Reviewers: A Cross-Sectional Study." Journal of Psychosomatic Research 78(1):7-11. https://doi.org/10.1016/j.jpsychores.2014.09.015.

Torvik, Vetle I., and Neil R. Smalheiser. 2009. "Author Name Disambiguation in MEDLINE." ACM Transactions on Knowledge Discovery from Data 3(3):11. https ://doi .org/10.1145/ 1552303.1552304.

West, Jevin D., Jennifer Jacquet, Molly M. King, Shelley J. Correll, and Carl T. Bergstrom. 2013. "The Role of Gender in Scholarly Authorship." PLoS ONE 8(7):e66212. https: //doi.org/10.1371/journal.pone.0066212.

Xie, Yu, and Kimberlee A. Shauman. 1998. "Sex Differences in Research Productivity: New Evidence about an Old Puzzle." American Sociological Review 63(6):847. https : //doi.org/10.2307/2657505.

Xie, Yu, and Kimberlee A. Shauman. 2003. Women in Science: Career Processes and Outcomes. Boston, MA: Harvard University Press.

Zucker, Lynne G., Michael R. Darby, and Maximo Torero. 2002. "Labor Mobility from Academe to Commerce." Journal of Labor Economics 20(3):629-60. https : //doi .org/10. $1086 / 339613$. 
Acknowledgments: Address all correspondence to freda-lynn@uiowa.edu. Azoulay acknowledges the financial support of the National Science Foundation through its SciSIP Program (Award SBE-1460344). Soomi Kim provided exceptional research assistance. We thank Ezra Zuckerman for useful discussions. The authors contributed equally, and all errors are our own.

Pierre Azoulay: MIT Sloan School of Management, Massachusetts Institute of Technology, and National Bureau of Economic Research. E-mail: pazoulay@mit.edu.

Freda B. Lynn: Department of Sociology and Criminology, University of Iowa. E-mail: freda-lynn@uiowa.edu. 